\title{
THE DEGREE OF READINESS AT GOVERNMENT SCHOOLS TO IMPLEMENT THE OMANI CHILD LAW: A CASE STUDY ON THE PRINCIPALS' PERSPECTIVES AT SECOND CYCLE SCHOOLS IN SAHAM
}

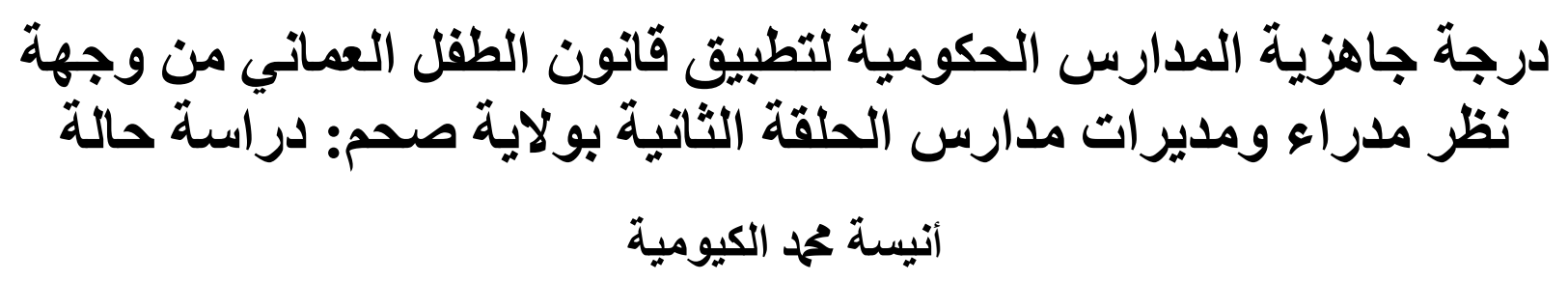

\section{Anisa Mohammed Alkyumi ${ }^{1 *}$, Kawthar Abdalla Ma. Bayoumi ${ }^{2} \&$ Dr. Nesreen Saleh Mohamed Salah EL-Din ${ }^{3}$}

${ }^{1}$ Ph.D. Candidate at the Faculty of Education, Islamic Civilization Academy, Universiti Teknologi Malaysia (UTM): Anisa.alkyomi44@moe.om

${ }^{2}$ Dr., Senior lecture at the Faculty of Education, Islamic Civilization Academy, Universiti Teknologi Malaysia (UTM), amkawthar@utm.my

${ }^{3}$ Senior lecture at Sultan Qaboos University, Oman: nesren@squ.edu.om

* Corresponding Author

\begin{abstract}
This case study aimed to reveal the degree of readiness in the second cycle schools at Wilayat Saham; to implement the Omani Child Law, from the school principals' perspectives. The problem emerged; that $44.5 \%$ of students were assaulted during their childhood, of which $48 \%$ were beaten, $19 \%$ sexually abused, $18 \%$ verbally insulted. And that 765 Omani children who were juvenile offenders were aged (9-17) years. An analytical descriptive approach was used, data was collected through a questionnaire, designed in three axes: Laws and Regulations axis, Curriculum axis, and School building axis. The questionnaire was applied to a sample of 17 Male and female principals of a second cycle school in the Wilayat of Saham in the Sultanate of Oman. The findings of the statistical analysis showed that: the axis of laws and regulations got the highest arithmetic mean, while the axis of the building got the lowest arithmetic mean. The findings also showed that the readiness of government schools to implement the Child Law is average, and indicated that there were no statistically significant differences at the level $(0.005 \leq \alpha)$ between the responses of the male and female study sample, as well as the absence of statistically significant differences due to the variable years of experience.
\end{abstract}

Keywords: implementation, child law, school readiness.

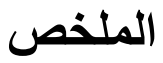

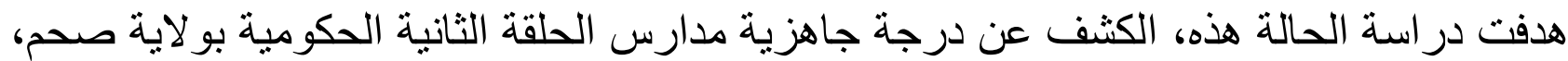

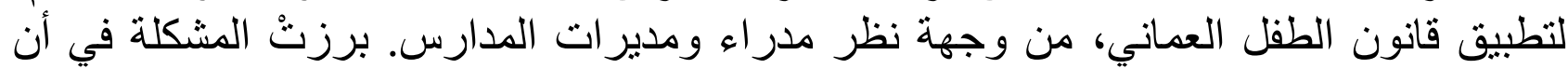
44,5 من الطلبة قد تعرضو اللاعتداء في طفولتهم، منها 48\% الضرب، 19 19 اعتداء جنسي، 


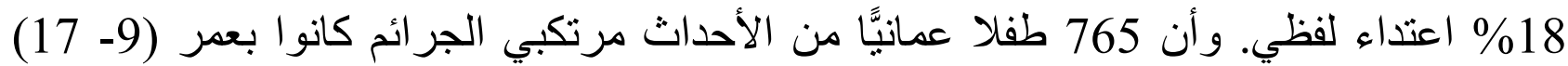

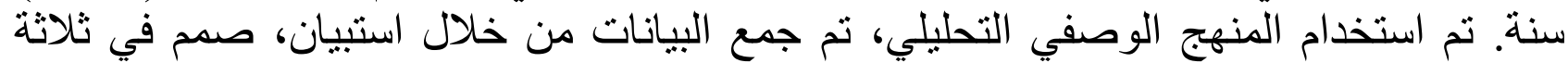

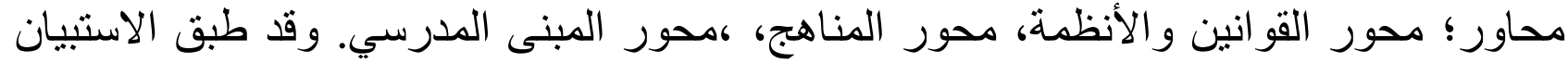

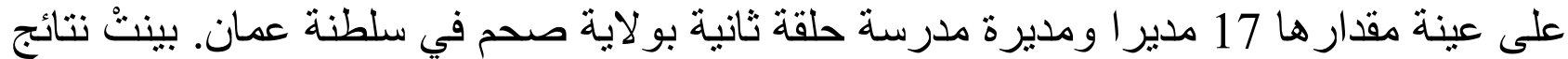

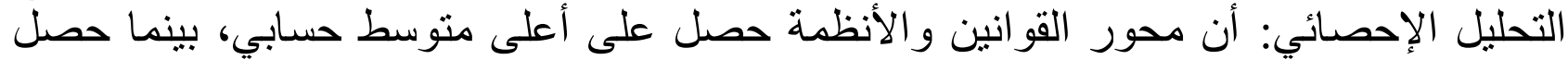

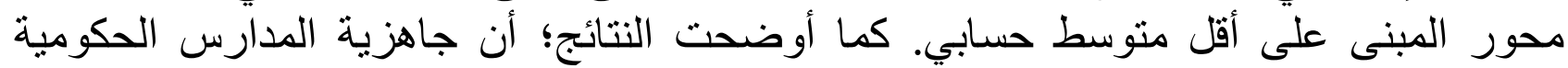

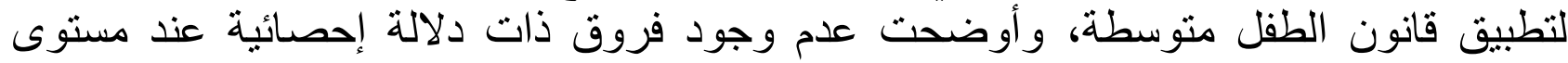

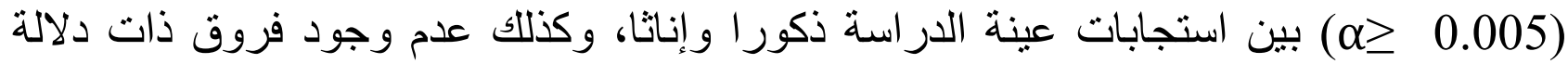
إحصائية تعزى لمتغير سنو ات العمل. الكلمات المفتاحية: تطبيق، قانون الطفل، جاهزية المدارس.

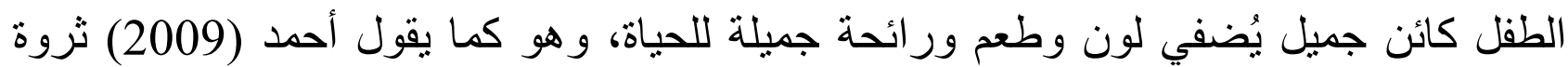

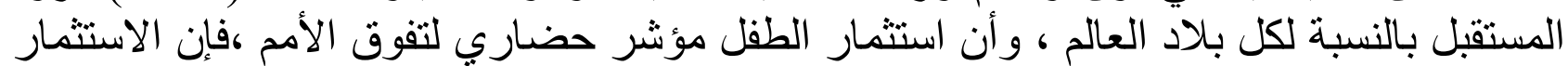

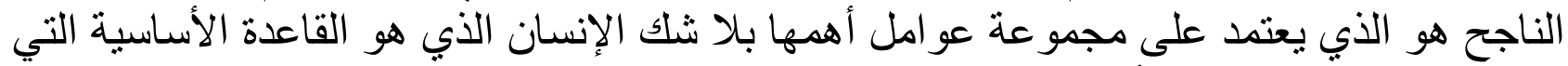

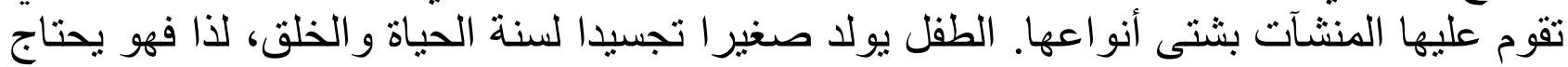

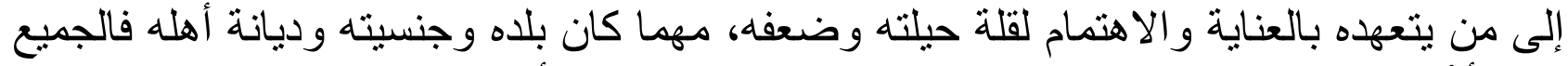

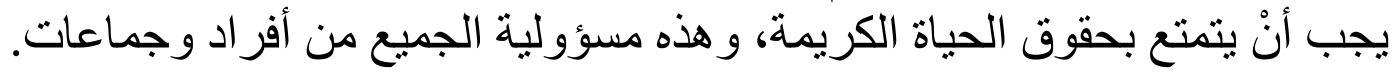

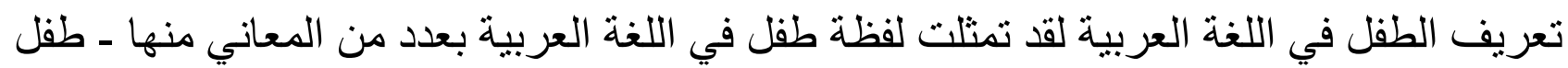

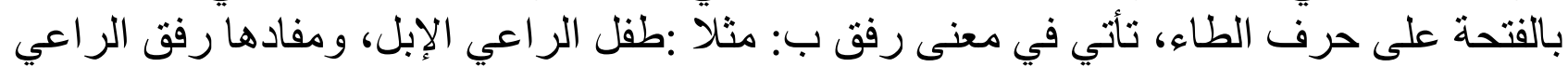

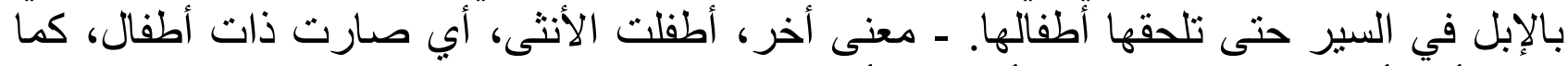

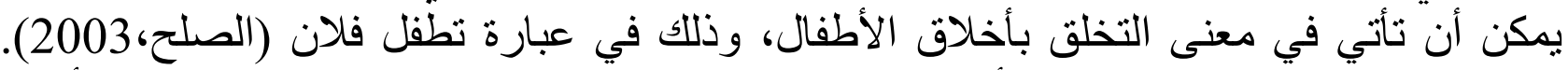

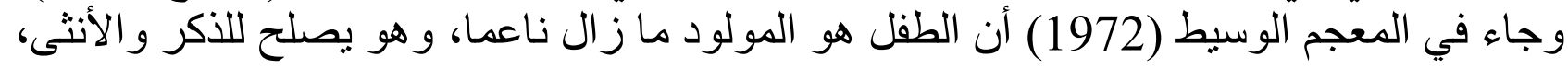

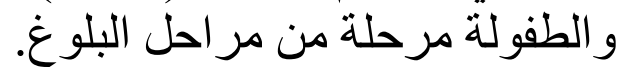

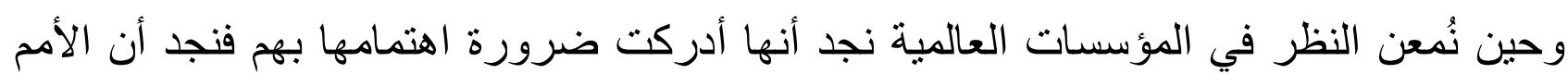

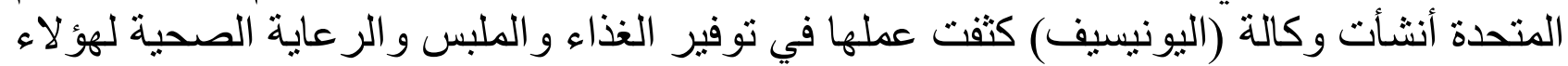

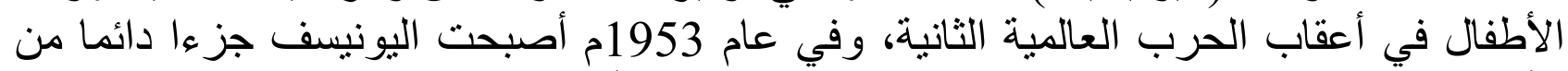

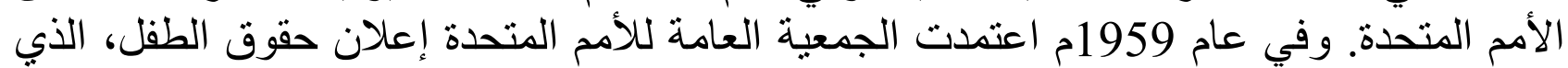

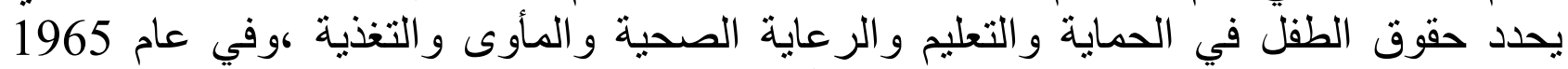

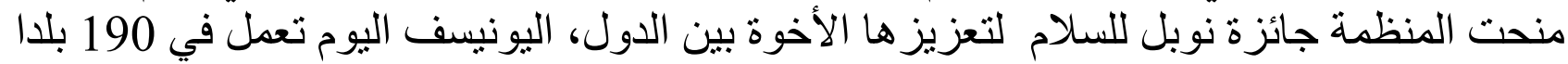

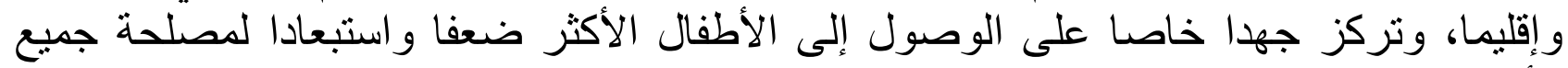

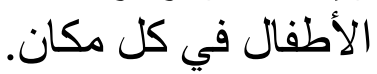

سلطنة عمان من الدول التي أولت اهتماما بالطفل وأصدرت قانون الأون لحمايته عام 2014 بمرسوم

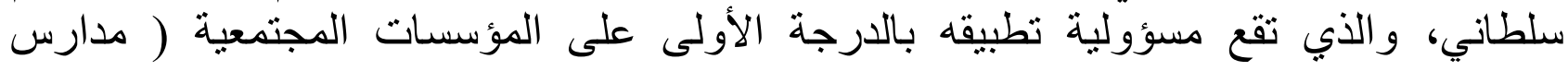




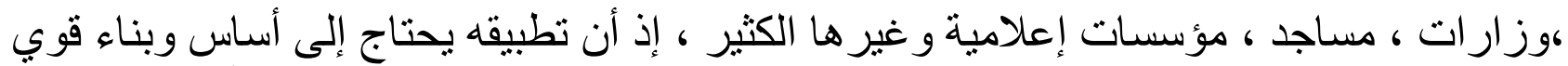

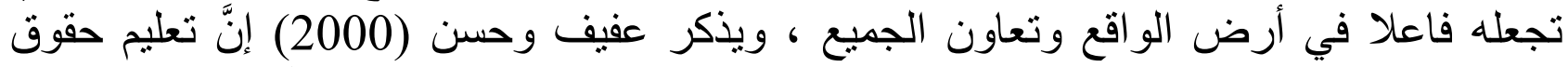

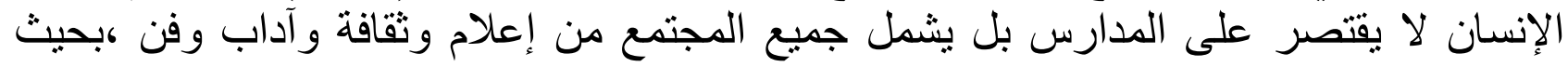

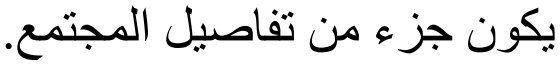
مشكلة الدراسة:

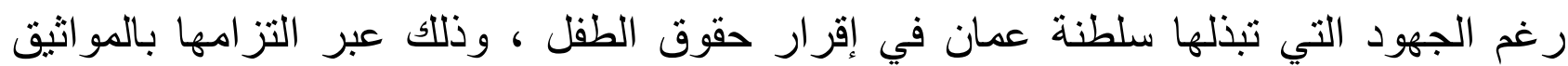

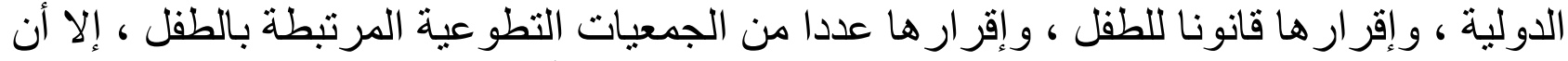

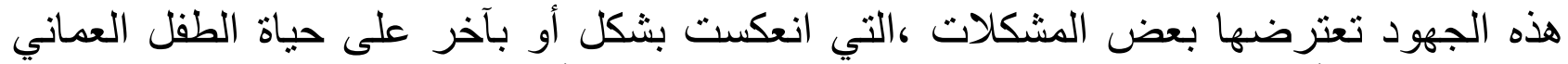

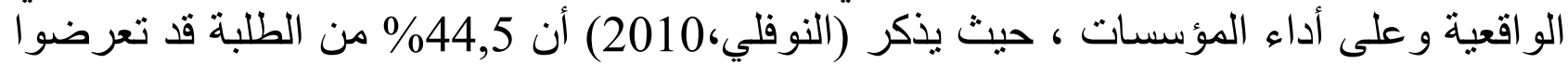

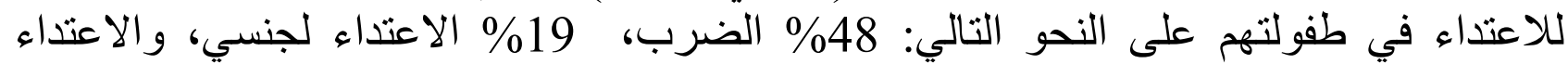

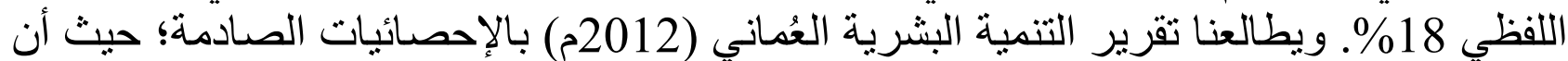

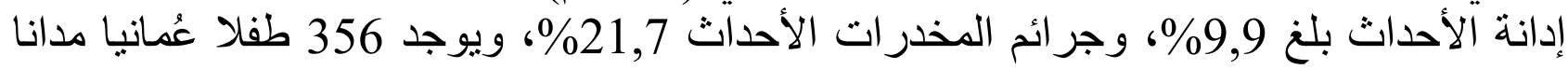

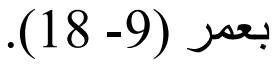

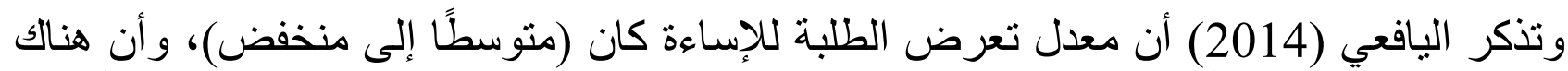

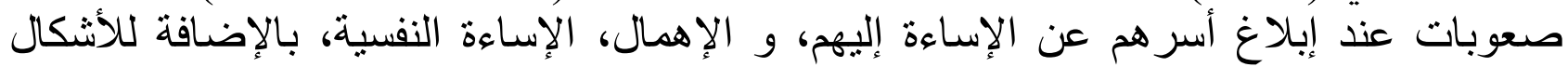

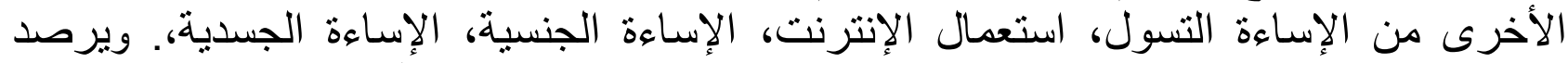

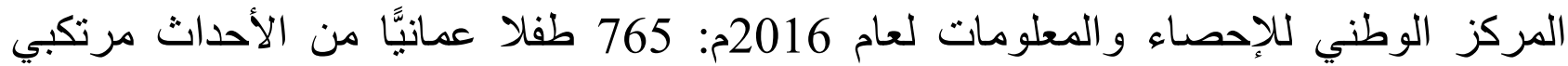

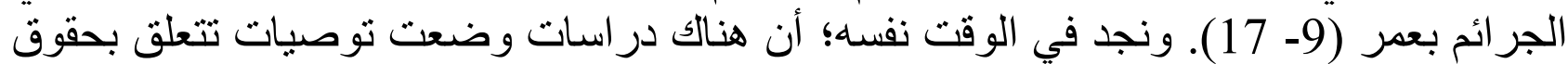

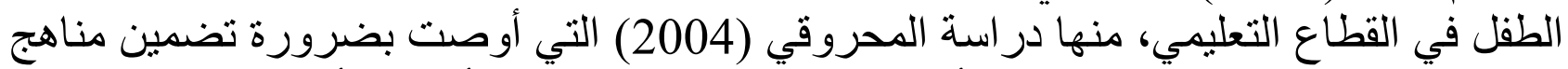

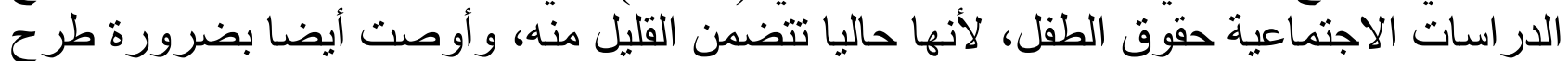

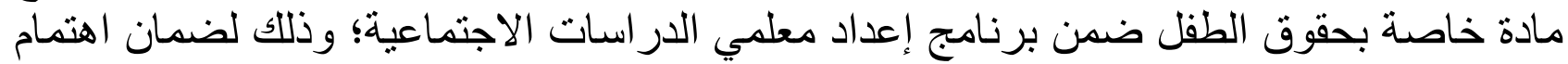

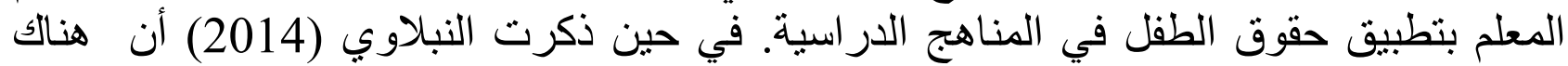

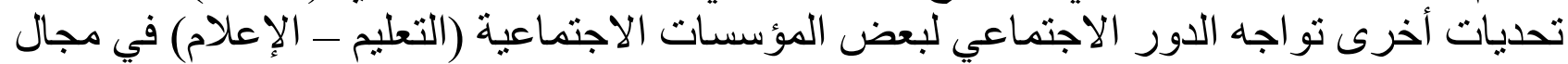

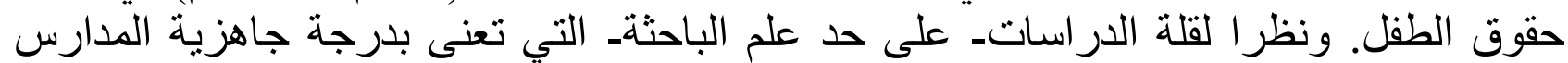

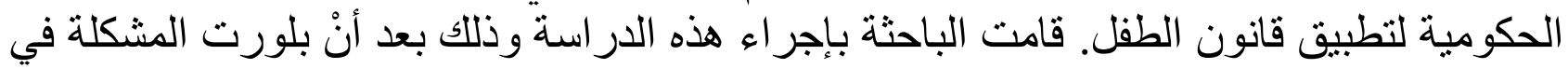

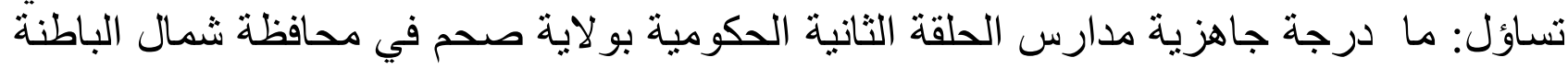

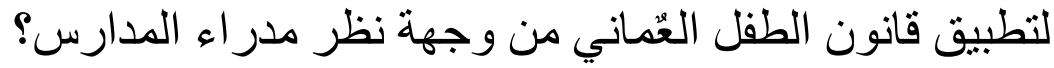

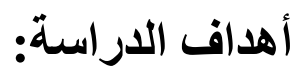

أ. تحليل درجة جاهزية مدارس الحلقة الثانية الحكومية، بو لاية صحم في محافظة شمال الباطنة،

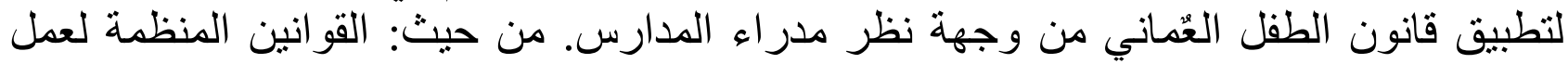
المدارس، المناهج الدر اسية، ملائمة المبنى المدئ المدرسي. ب. تشخيص الفروق ذات الدلالة الإحصائية، في النظرة لجاهزية المدارس الحكومية؛ تعزى لمتغير النوع الاجنماعي. ت. تشخيص الفروق ذات الدلالة الإحصائية، في النظرة لجاهزية المدارس الحكومية؛ تعزى لمتغير سنوات العمل كمدير مدرسة. 


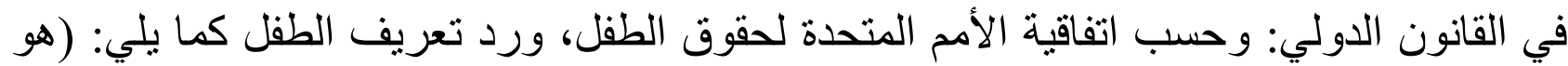

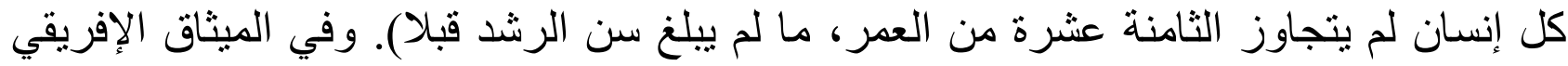

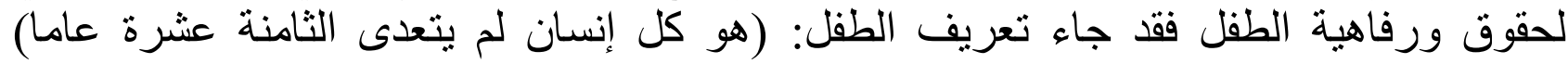
رة كل

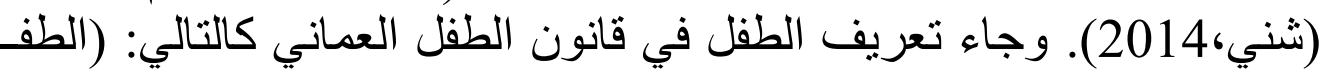
إنسان لم يكمل الثامنة عشرة من العمر بالتقويم الميلادي).

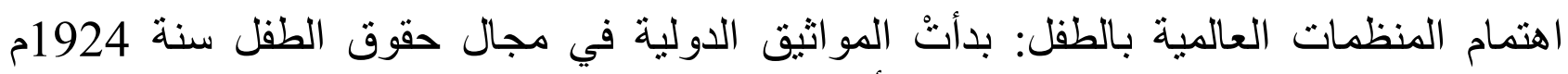

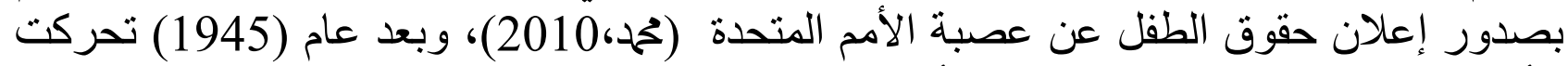

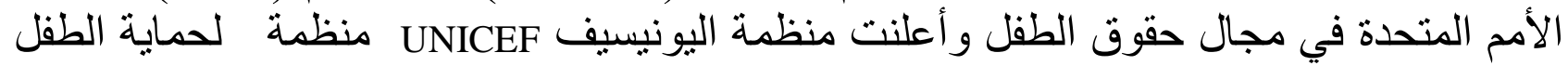

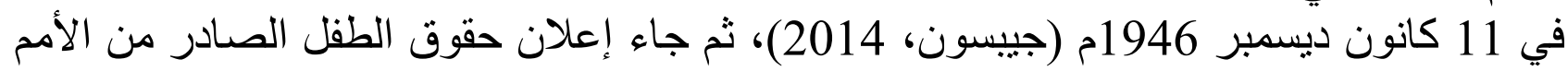

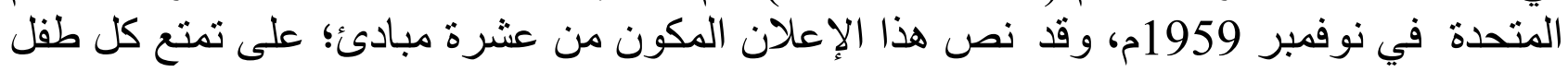

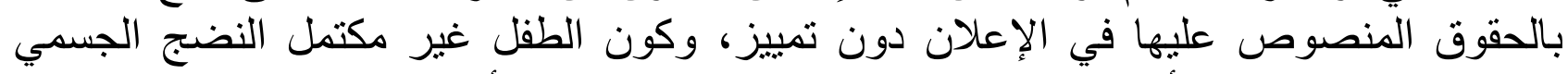

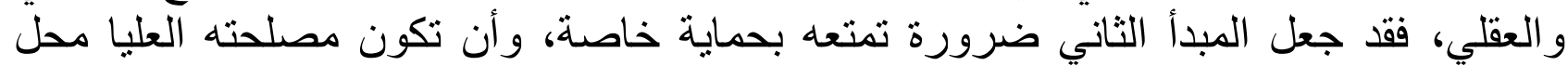

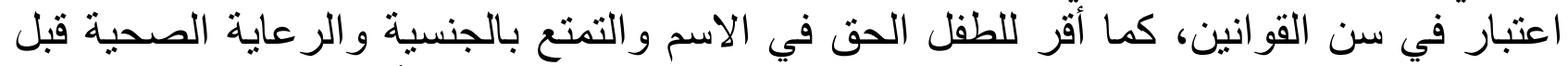

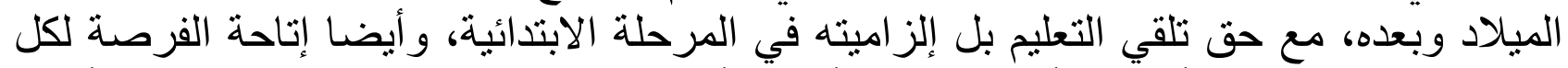

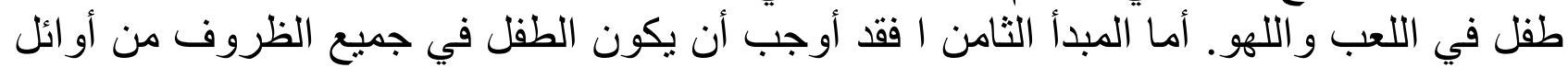

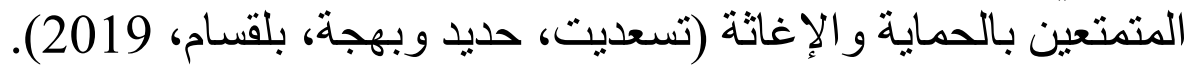

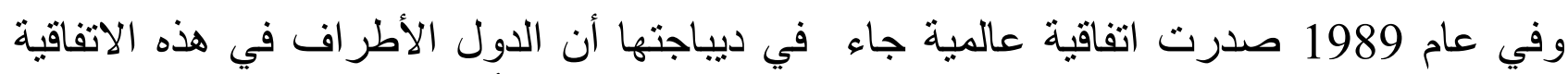

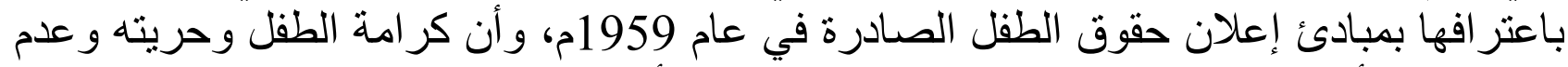

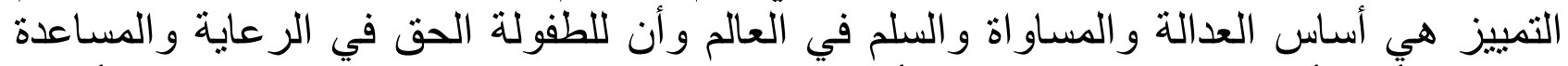

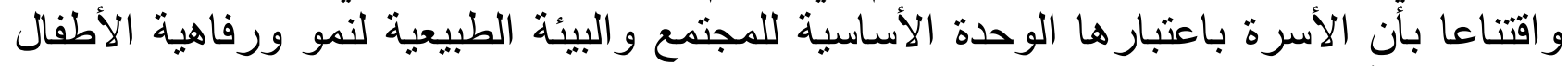

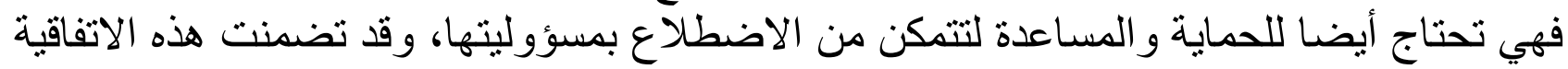

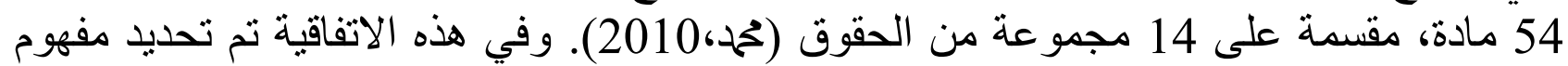

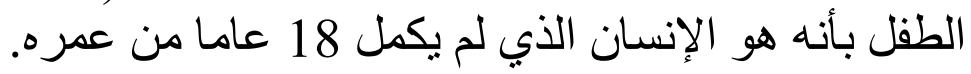

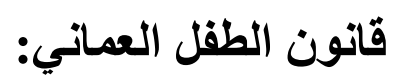

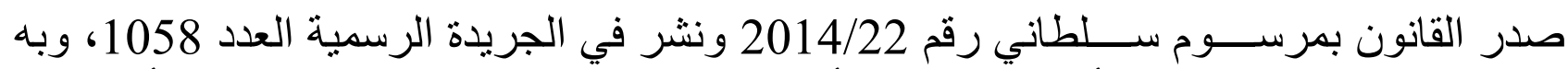

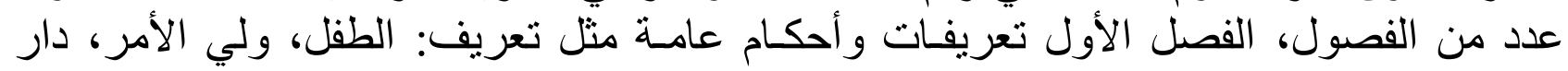

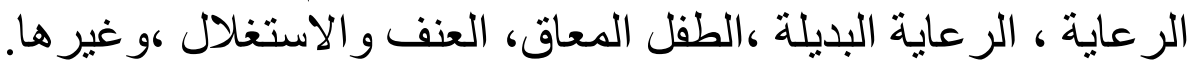

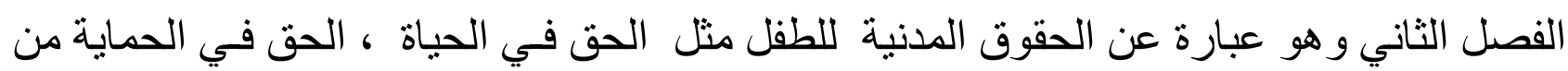

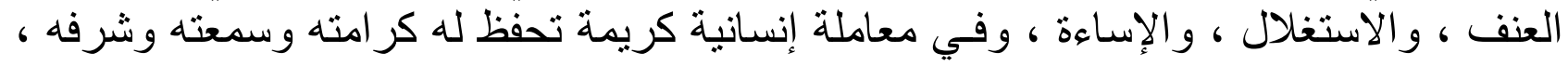

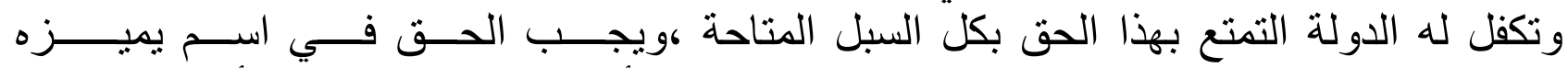

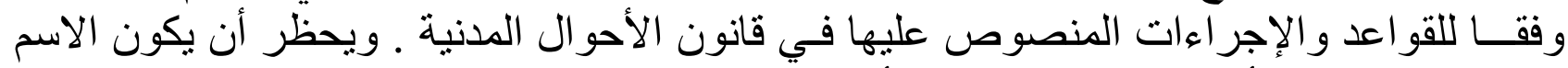
منطويا على تحقير أو مهانة لكر امة الطفل أو منافيا للعقائد الدينية.

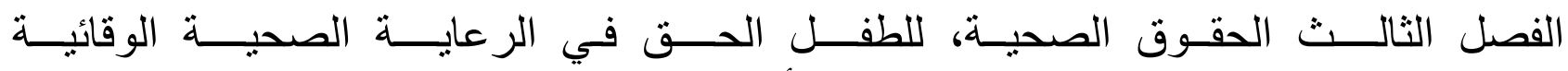

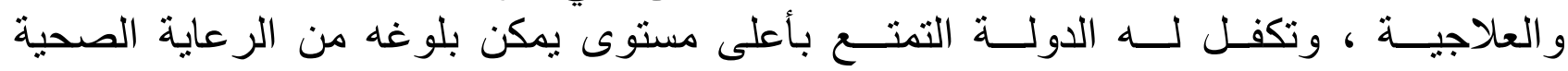


المجانية و غير ها الكثير

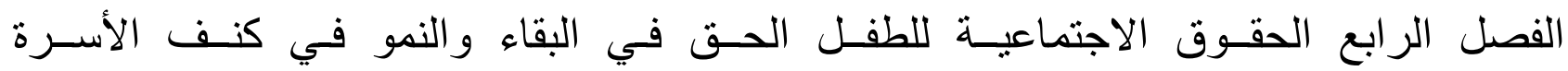

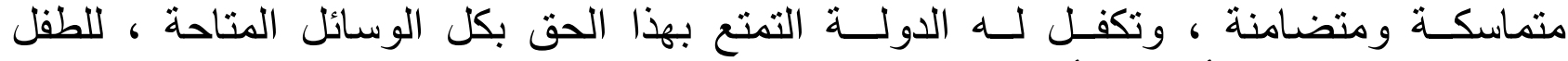

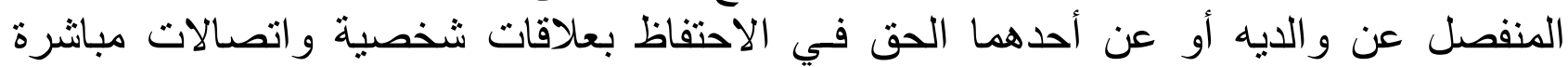

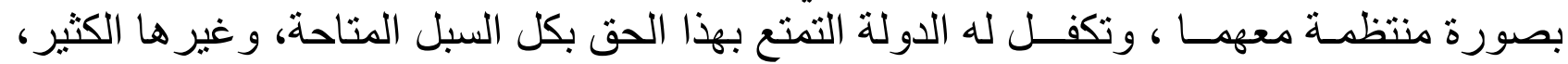

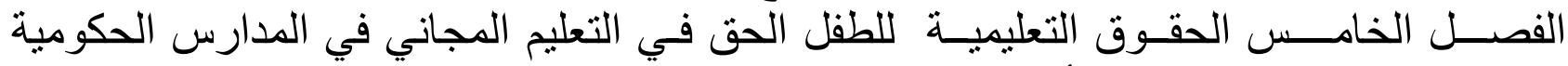

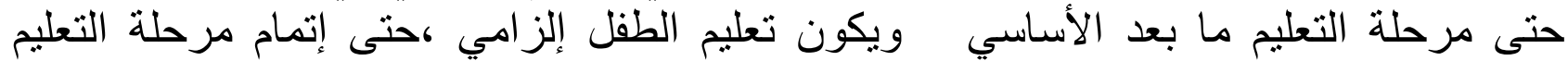

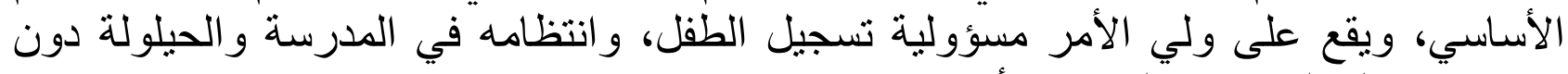
تسربه، و هناك العديد من الحقوق الأخرى.

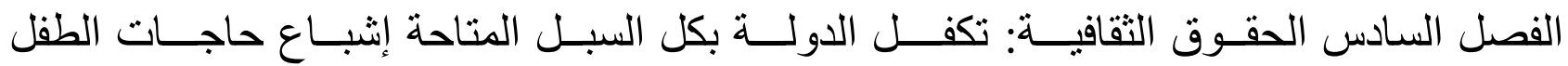

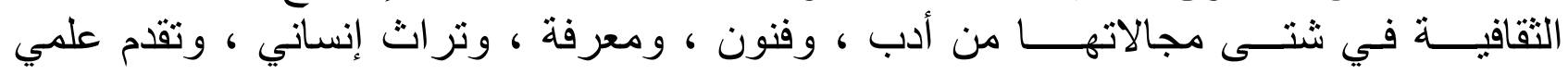

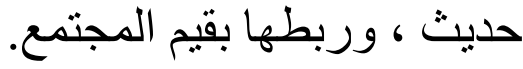

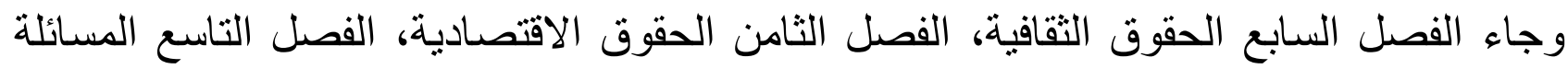

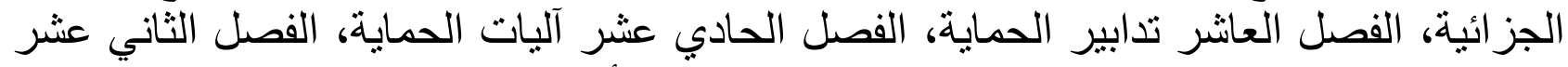
العقوبات و التعويضات المدنية، الفصل الثالث عثر يتضنمن أحكاما ختامية.

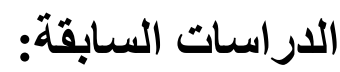

دراسة المحروقي، (2004): هدفت الدراسة للكثف عن مدى تضمين كتب الدراسات الاجتماعية

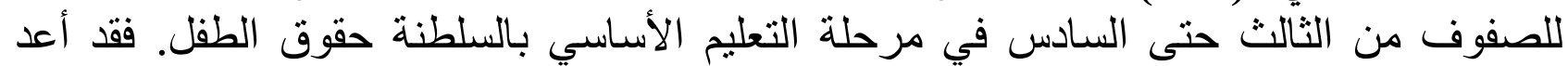

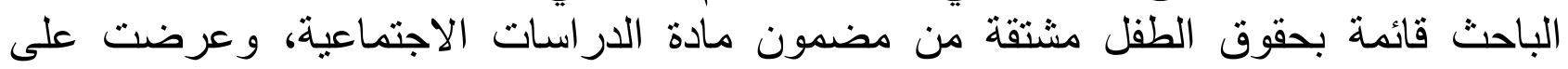

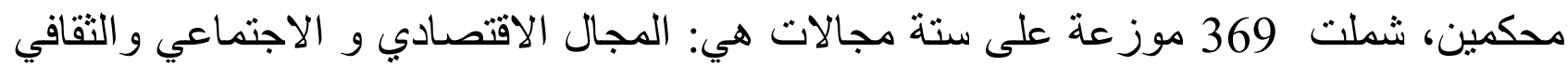

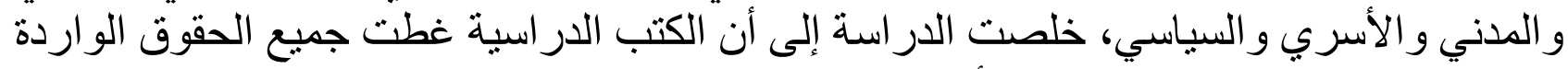

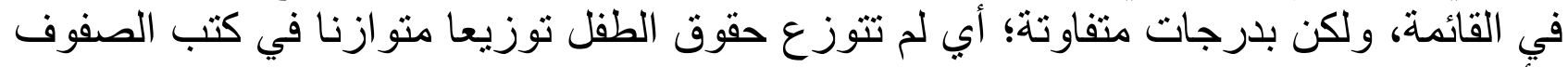

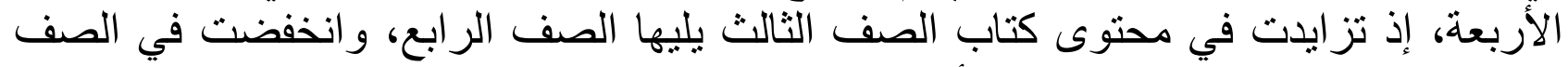

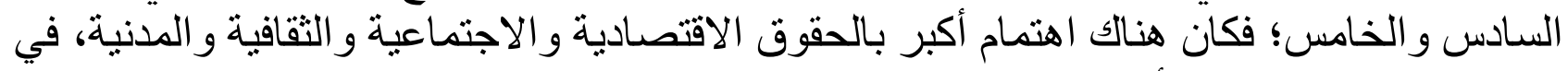

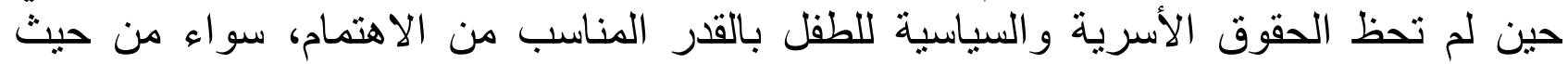

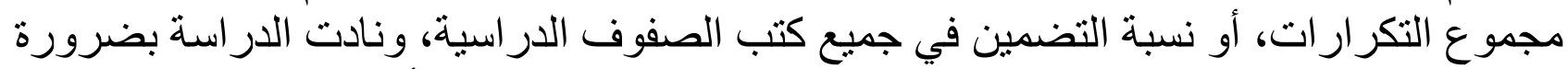

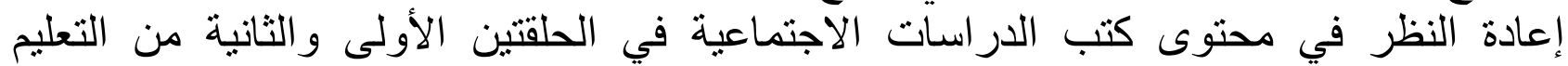

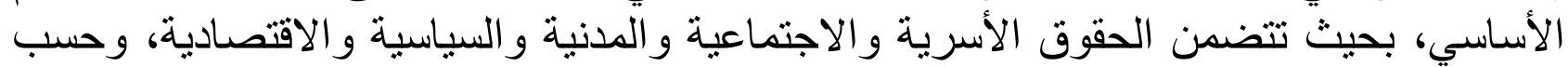

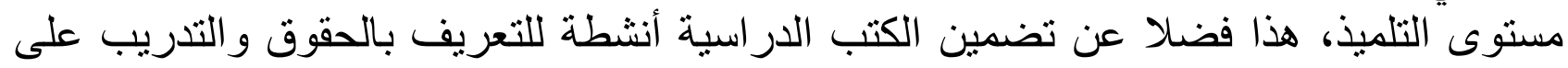

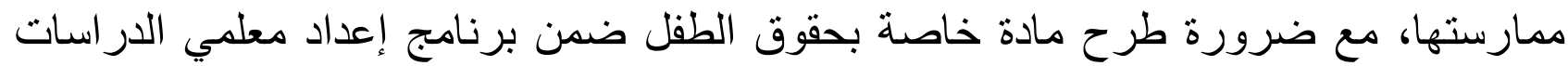

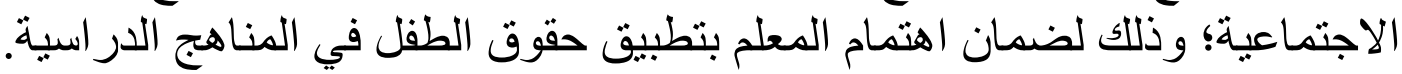

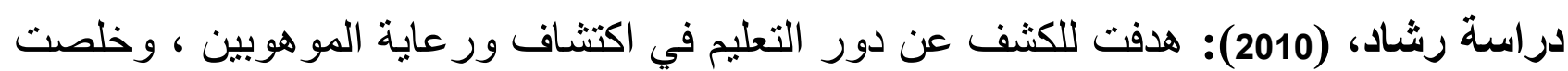

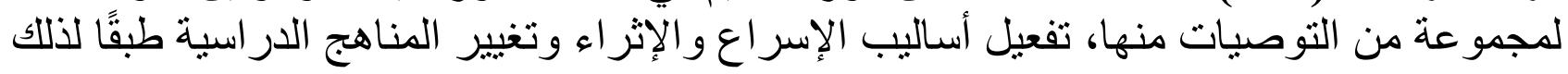

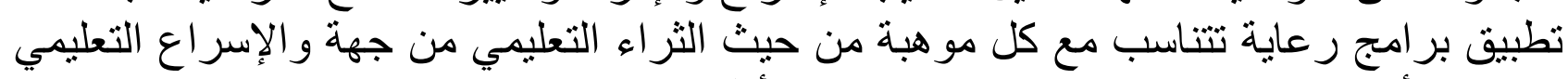

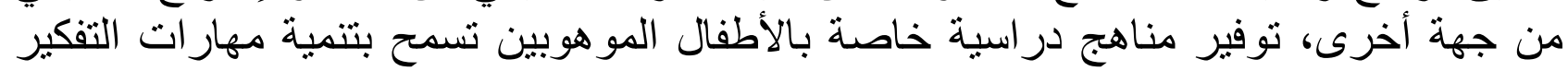


الناقد، و اكثناف المعارف الجديدة وتشجع على الابتكار، و التميز، و التعلم و النمو الذاتي، فضلا عن تضمينها لأساليب تقويمية مطورة لتقويم أداء ومهار ات التلاميذ، تفعيل دور نو ادي العلّوم و إمدادها بالخامات و الأدوات التي تعين الطالب على الاكتشاف و البحث و التجريب، وهي من المتطلبات الخاصة لـإبداصاع.

دراسة النبلاوي، (2012): هدفت الدراسة إلى معرفة دور البنى المؤسسية والمجتمعية في توفير

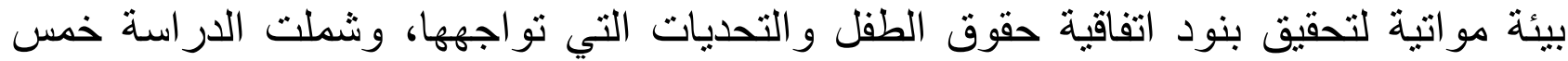

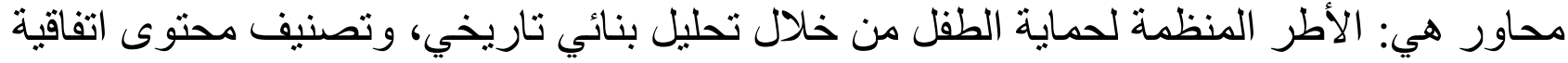
حقوق الطفل وبيان ما تحويه من مضامين تستهدف حماية الطفل ور عايته، و الطفل في القوانين وين فئن

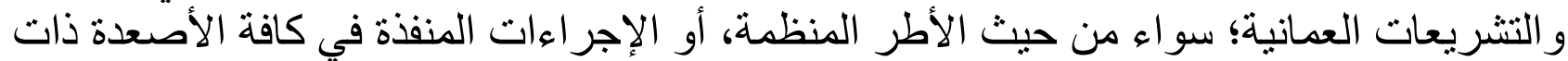

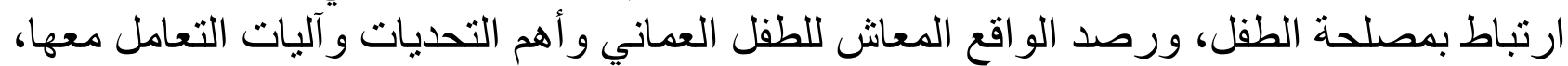
وكذلك در اسة و اقع الطفل من ذوي الإعاقة، استخدمت الدراسة زيار ات مبدانية لعدد من الأسر

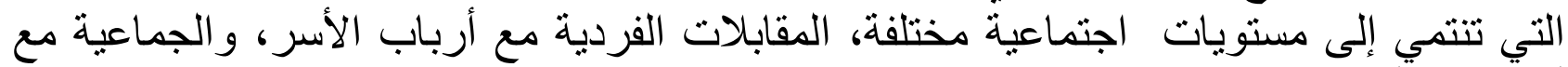
أعضاء الأسرة، فضلا عن مقابلات مع بعض القيادات النسائية المحلية، وموظفي وزارة التيهية الاجتماعية، خلصت الدراسة إلى أن التشريعات و القوانين العمانية مهدت لبعض الته التغييرات تستهدف توفير ضمانات لحقوق الطفل، بينما يشهد الواقع بعض التحديات منها ما يرتبط بآليات

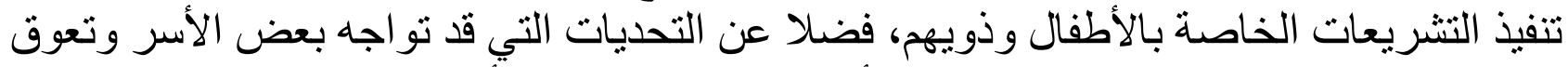

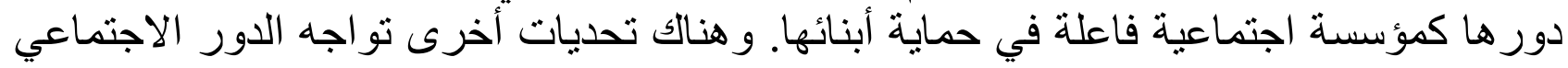

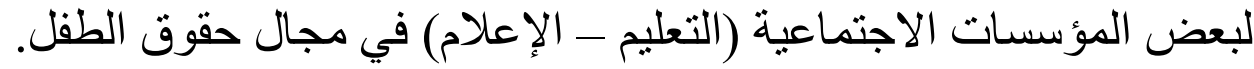

دراسة عبدالمجيد (2013): هدفت إلى الكثف عن الجدوى المدكنة من تطوير إمكانيات الأطفال

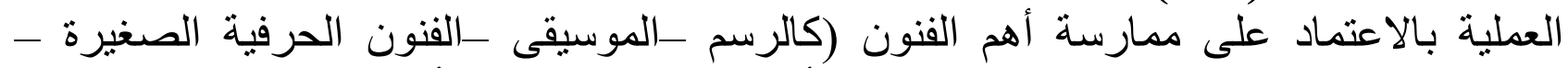
الإدر الك البصري )، و اعتمد البحث على وضع أهم النماذج العالمية و الأكاديمية التي يمكن توفير ها

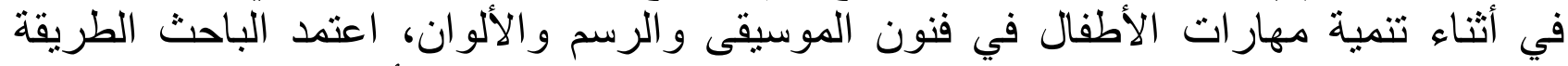
التحليلية (Research Analytical) في منهجية البحث ، و استخدم بعض فين الأدوات الخاصة في تنفيذ

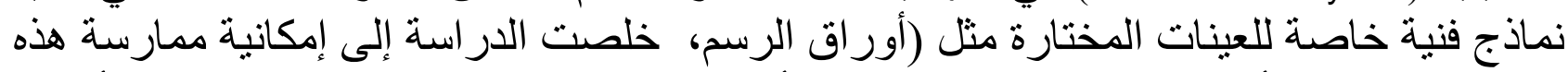
الفنون بالطريقة الأكاديمية الصحيحة لمختلف الأعمار ، إضافة إلى إمكانية تحليل بعض الفانه الأعمال الفنية الخاصة للأطفال الذين لم يتجاوزوا إحدى عثرة سنة، و اكتشاف مهار اتهم الفكرية والنفسية من خلال هذه الفنون. منهج الاراسة: انطلاقاً من مشكلة الدراسة وأهدافها وطبيعة تساؤلاتها، قامت الباحثة باستخدام المنهج الوصفي

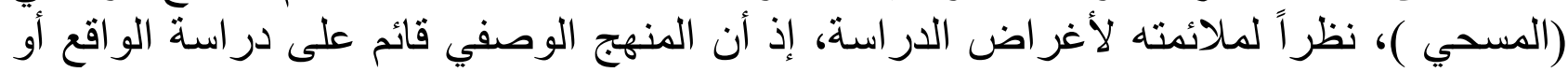

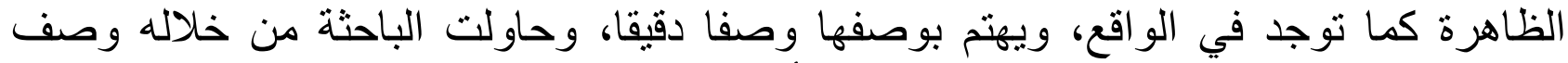
موضوع الدراسة، وتحليل البيانات وتفسير ها، أملا في التوصل إلى توصيات ذوات ذات معنى، تزيد

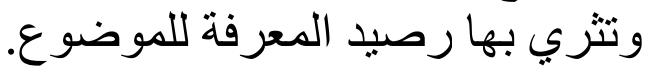
مجتمع الدراسة وعينتها: تكون مجتمع الدر اسة من جميع مدراء ومديرات مدارس الحلقة الثانية بولاية صحم، بمحافظة 


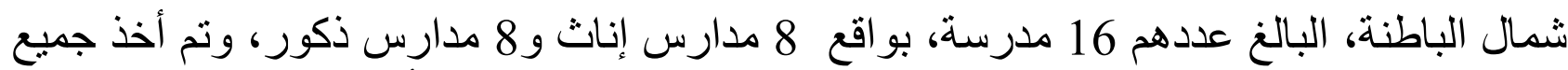

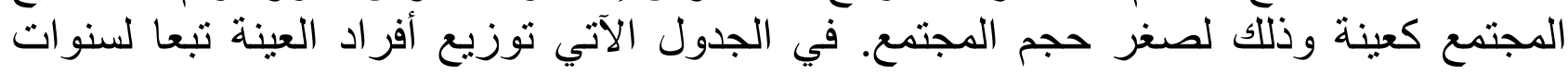
الخيرة.

جدول (1) توزيع عينة الدر اسة حسب سنوات العمل كمدير مدرسة

\begin{tabular}{|c|c|}
\hline العدد & السنوات \\
\hline 1 & $1-5$ \\
\hline 12 & $6-10$ \\
\hline 13 & 11 فأعلى \\
\hline 16 & المجموع \\
\hline
\end{tabular}

أداة الدراسة:

بعد الرجوع للأدب النظري، مثل دراسة المحروقي (2004)، رشاد (12010) و النباءوي (2002)؛ قامت الباحثة ببناء استبانة وفق المقياس الثناثي، تكونت من (17) فقرة موزعة على على ثلاثلث محاور هي: أ. محور القوانين والأنظمة، يحتوي الفقر ات (1-5). ب. محور المناهج، يحتوي الفقرات (12-6).

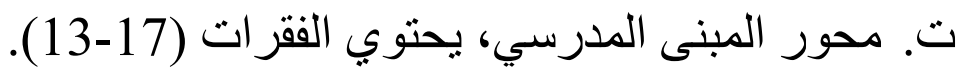

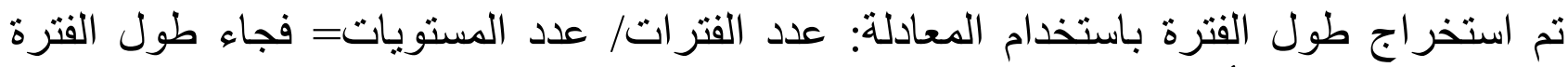
(67.)، و على هذا الأساس تكون مستويات المتوسطات الحسابية ثناثنة:

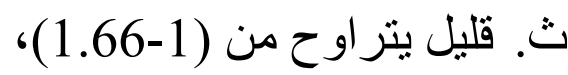

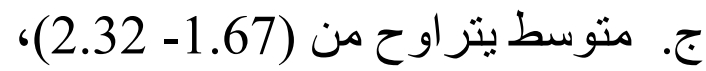
ح. كبير يتراوح من (2.33- 3. 3.

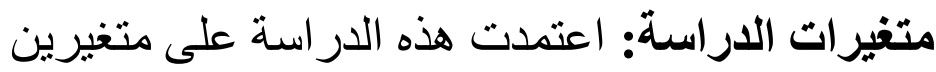
الأول: متغير ات مستقلة:

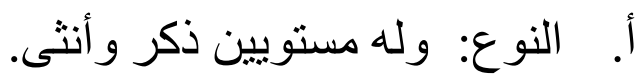

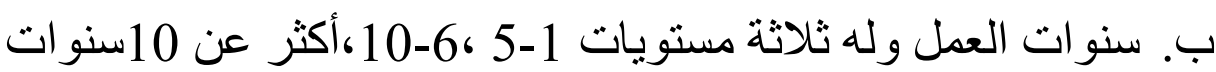
الثاني: المتغير التابع هو درجة جاهزية المدارس الحكومية لتطبيق قانون الطفل العماني 
صدق الأداة للاراسة: للتحقق من صدق الأداة، عرضت الاستبانة على محكمين من ذوي الخبرة

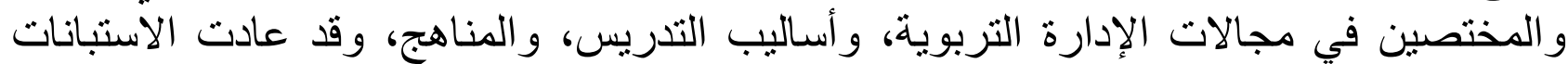

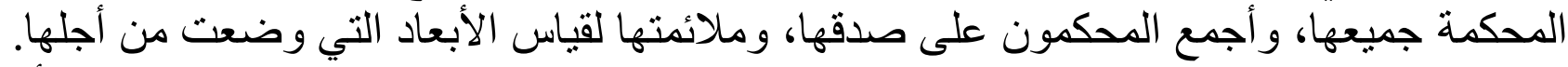

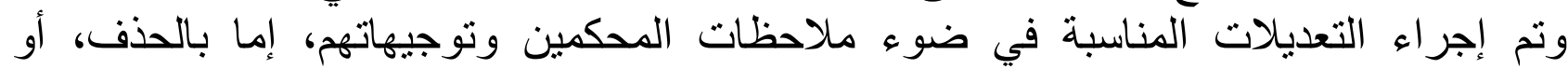

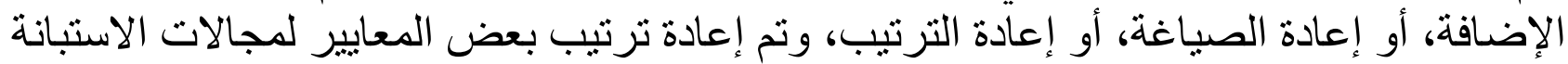
في صورتها النهائية.

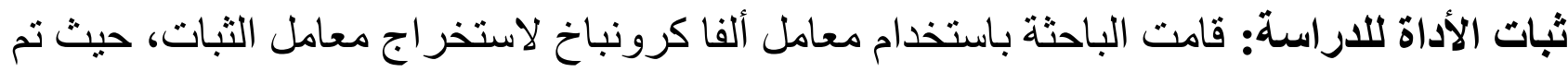

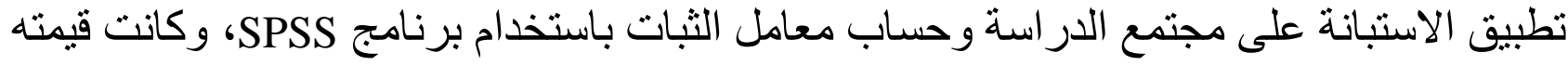
(0.919) و هي قيمة مدنازة. المعالجات الإحصائية: نم إدخال البيانات في الحاسب الإنة الآلي على البرنامج الإحصائي SPSS مع

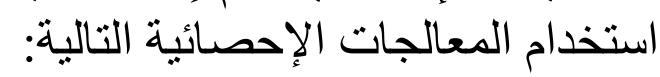

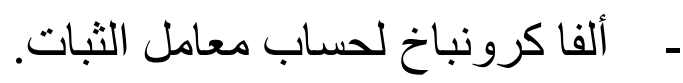
- - المتوسطات الحسابية والانحر افات المعيارية. - - اختبار (ت) لدراسة الفروق بين متوسطات استجابات أفراد مجتمع الدراسة تعزى لمتغير النوع.

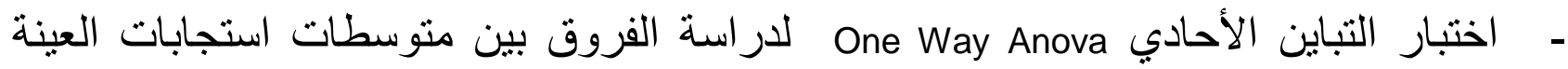
تعزى لمتغير سنوات العمل. عرض وتحليل نتائج الدراسة وتحليلها للإجابة عن السؤال الأول الذي نصده: ما درجة جاهزية المدارس الحكومية لتطبيق قانون الطفل

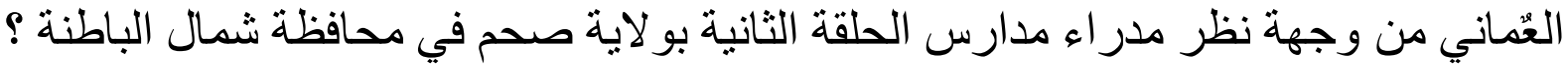
للإجابة عن هذا التساؤل تم حساب المنوسطات الحسابية والانحر افات المعيارية، لجميع محاور الاستبانة، كما في الجدول الآتي:

جدول (2) المتوسطات والانحر افات المعيارية لكل محور

\begin{tabular}{|c|c|c|c|c|}
\hline الرتبة & الانحراف المعياري & الحستبابي & المحور & $ت$ \\
\hline 1 & .59104 & 2.15 & القو انين و الأنظمة & 1 \\
\hline 2 & .50358 & 2.0104 & المناهج & 2 \\
\hline 3 & .51953 & 1.6042 & المبنى & 3 \\
\hline & & 1.9081 & المعدل & \\
\hline
\end{tabular}

يتضح من الجدول (2) أعلاه أن جاهزية المدارس الحكومية لتطبيق قانون الطفل جاءتْ بدرجة إنها

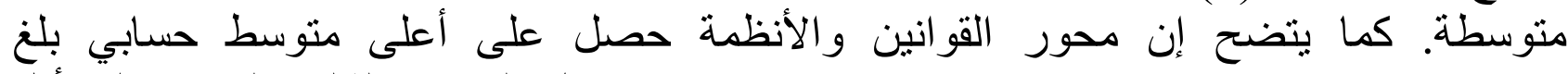

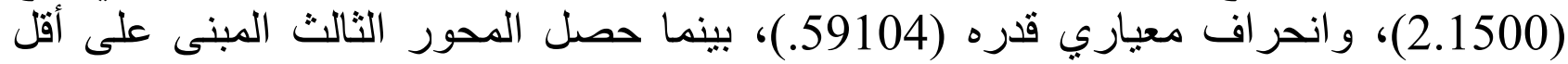

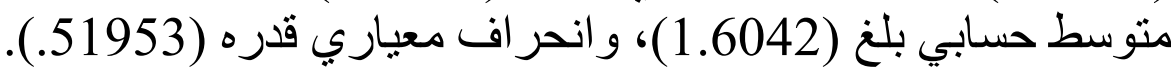
عرض نتائج المحور الأول (القوانين والأنظمة): 
الجدول (3) المتوسطات الحسابية لفقرات المحور الثاني (القو انين والأنظمة)

\begin{tabular}{|c|c|c|c|c|}
\hline الرتبة & الانحراف افياري & المتوسط الحسب & الفقــرة & ت \\
\hline 2 & .68313 & 2.2500 & تتسجم لائحة تنظيم شؤون الطلبة مع قانون الطفل & 1 \\
\hline 4 & .51640 & 2.0000 & تتناسب قو انين عمل الجمعيات التعاونية مع قانون الطفل & 2 \\
\hline 1 & .71880 & 2.3750 & تُسـاند قو انين عمل الأخصائي الاجتماعي تطبيق قانون & 3 \\
\hline 3 & .80623 & 2.1250 & الطناسب العماني. القين المنظمة لأوقات دو ام الطلبة مع قانون & 4 \\
\hline 5 & .63246 & 2.0000 & تحفظ عقود استنئجار الحافلات المدرسية حقوق الطلبة. & 5 \\
\hline & .59104 & 2.15 & المعدل & \\
\hline
\end{tabular}

يتضح من الجدول (3) أن تأثثر المحور الأول في جاهزية المدارس الحكومية لتطبيق قانون الطفل

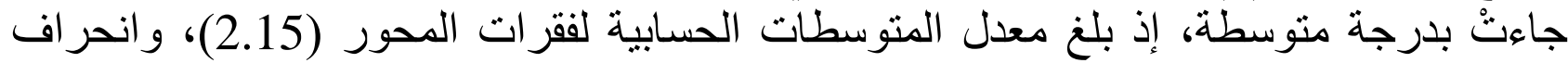

تبين أنّ عبارة (تُسـاند قوانين عمل الأخصائي الاجتماعي تطبيق قانون الطفل العماني) قد حصلت

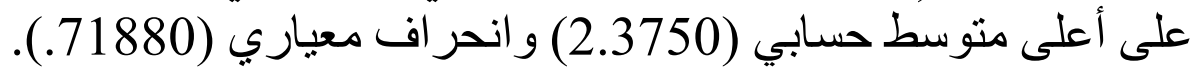
بينما كانت عبارة (تحفظ عقود استنجار الحافلات المدرسية حقوق الطلبة) الأقل بمتوسط حسابي (2.00) و انحر اف معياري (1) (1). عرض نتائج المحور الثاني (المناهج): تم استخر اج المتوسطات الحسابية والانحر افات لكل فقرة من فقرات المحور، كما في الجدول الآتي: الجدول (4) المتوسطات الحسابية لفقر ات المحور الثاني (المناهج)

\begin{tabular}{|c|c|c|c|c|}
\hline 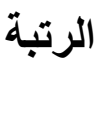 & 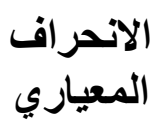 & المستوسط المسب & الفقـرة & ت \\
\hline 6 & .61914 & 1.6250 & تنشر المناهج الدر اسية ثقافة قانون الطفل العماني. & 1 \\
\hline 2 & .60208 & 2.3125 & ولثُمي المناهج الدر اسية احتر ام الطلبة لذويهم و هويتهم & 2 \\
\hline 5 & .70415 & 1.6875 & الخاستب المناهج الدر اسية احتياجات الطلبة ذوي الاحتياجات & 3 \\
\hline 4 & .61914 & 1.8750 & تُلبي المناهج الدر اسية احتياجات الطلبة المو هوبين. & 4 \\
\hline 3 & .57373 & 2.0625 & تُهيأ المناهج الدر اسية الطلبة للمستقبل . & 5 \\
\hline
\end{tabular}




\begin{tabular}{|c|c|c|c|c|}
\hline 1 & 63246 & 2.5000 & ثُرسخ المناهج الدراسية مبدأ المساواة بين البشر. 6 \\
\hline & $\mathbf{5 0 3 5 8}$ & $\mathbf{2 . 0 1 0 4}$ & $\mathbf{2 . 0 4}$ \\
\hline
\end{tabular}

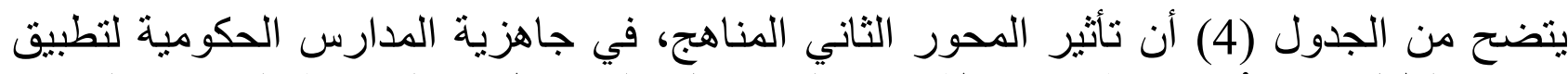

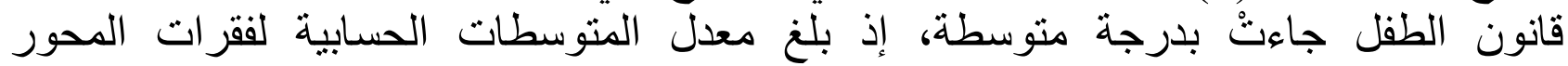

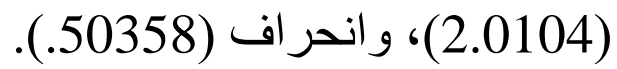

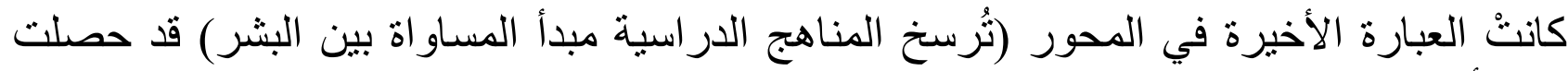

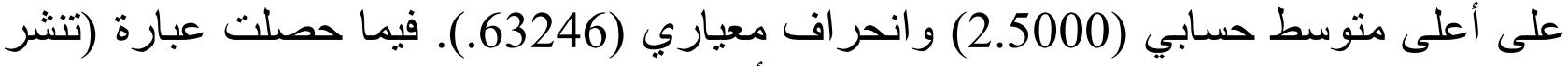

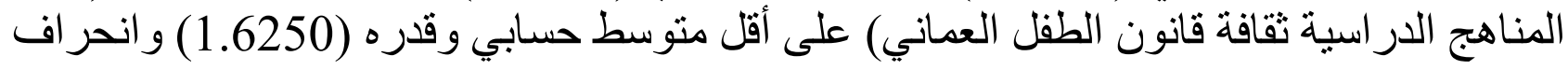
معياري (1919). (1914). عرض نتائج المحور الثالث (الأبنية): الجدول (5) المتوسطات الحسايية لفقرات المحور الثالث (الأبنية)

\begin{tabular}{|c|c|c|c|c|}
\hline الرتبة - الة & المعياري & الحسابي & الفقــرة & 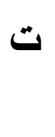 \\
\hline 2 & .7188 & 1.6250 & ليُوفر الر احة و الهدوء للطلبة . & 1 \\
\hline 2 & 99.7 & 1.6250 & يُوفر قاعات لممارسة هو ايات الطلبة. & 2 \\
\hline 3 & .72744 & 1.5625 & يُّناسب احتياجات طلبة الاحتياجات الخاصة. & 3 \\
\hline 2 & 582.7 & 1.6250 & يُّناسب الطلبة من ذوي الأمر اض المزمنة. & 4 \\
\hline 4 & .57735 & 1.2500 & المدرسية. على قاعات لاستقبال أبناء الموظفات دون سن دخول & 5 \\
\hline \multirow[t]{2}{*}{1} & .68007 & 1.9375 & يُشجع على ممارسة أنشطة خارج القاعات الصفية. & 6 \\
\hline & .51953 & 1.6042 & 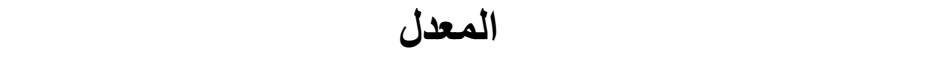 & \\
\hline
\end{tabular}

يتضح من الجدول (5) أن تأثثر المحور الثالث الأبنية المدرسية، في جاهزية المدارس الحكومية

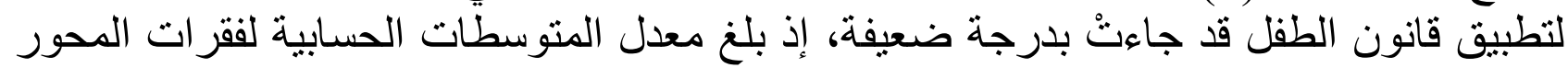

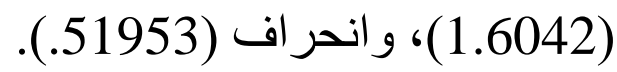

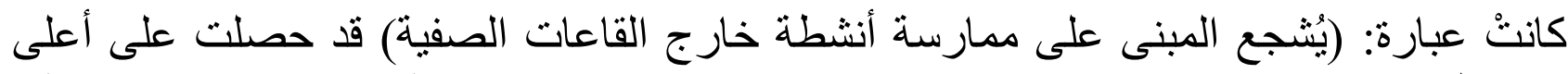

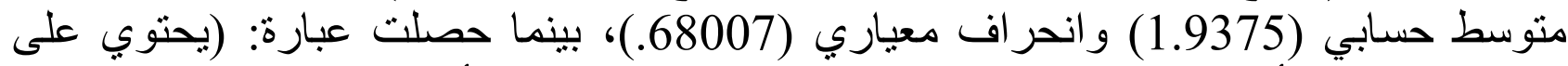
قاعات لاستقبال أبناء الموظفات دون سن دخول المدرسة) على أقل متوسط حسابي في هذا عان 


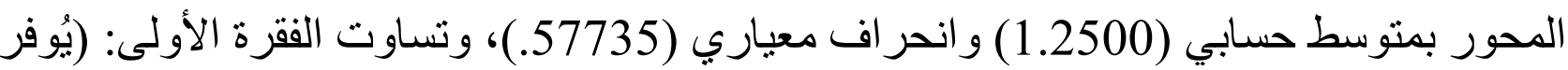

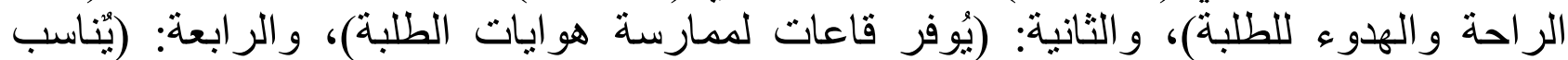

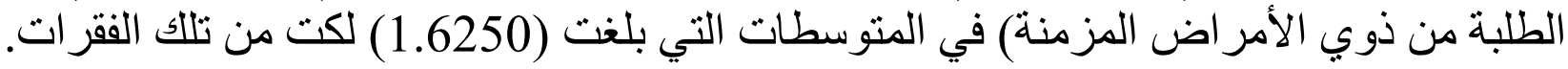

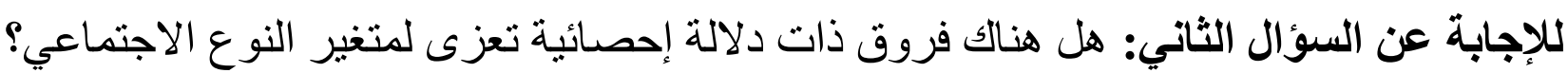

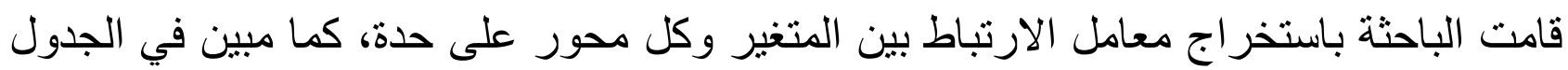
الآتي:

جدول (6) الكثف عن دلالة الفرق لدى عينة الدر اسة تبعا لمتغير النوع في محاور الاستبانة

\begin{tabular}{|c|c|c|}
\hline الدالة & قيمة معامل الارتباط & المحور \\
\hline غير دالة إحصـائيا & .344 & القو انين و الأنظمة \\
\hline غير دالة إحصائيا & .945 & المناهج \\
\hline غير دالة إحصـائيا & .381 & المبنى \\
\hline
\end{tabular}

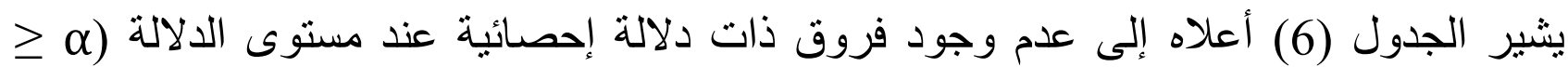

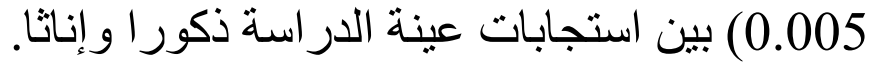
للإجابة عن السؤال الثالث: هل هناك فروق ذابنه ذات دلالة إحصائية لجاهزية المدارس الحكومية

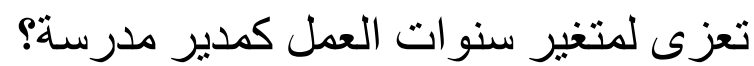
قامت الباحثة بإجر اء تحليل التباين الأحادي، و الجدول الآتي يبين نتائج هذا التحليل. جدول (7) الكثف عن دلالة الفرق لاى عينة الدر اسة تبعا لمتغير الخبرة في محاور الاستبانة

\begin{tabular}{|c|c|c|}
\hline الدلالة & قيمة ف & المحور \\
\hline غير دالة إحصائيا & .898 & القو انين و الأنظمة \\
\hline غير دالة إحصائيا & .608 & المناهج \\
\hline غير دالة إحصائيا & .606 & المبنى \\
\hline
\end{tabular}

يثير الجدول (7) أعلاه إلى عدم وجود فروق ذات دلالة إحصائية تعزى لمتغير سنوات العمل و الخبرة.

مناقشة النتائج: 


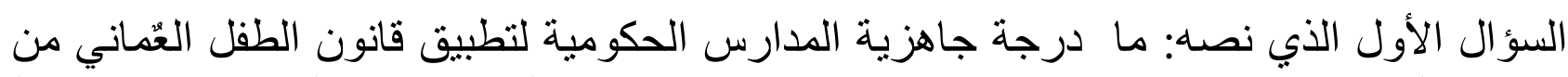

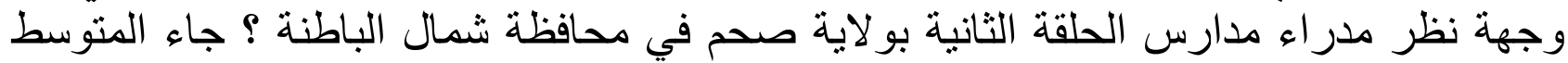

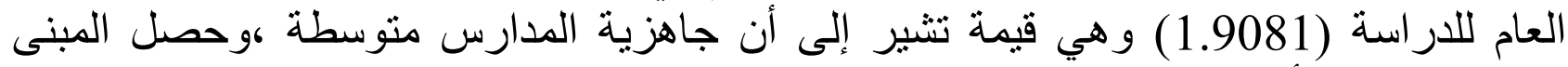

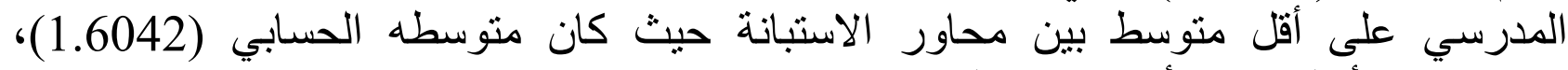
و القو انين و الأنظمة على أعلى منوسط حسابي (2.1500).

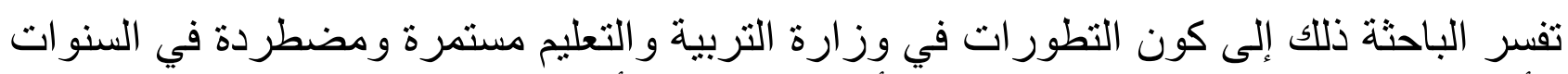

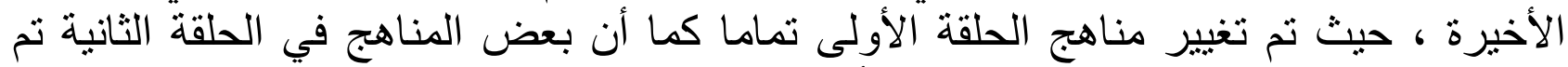

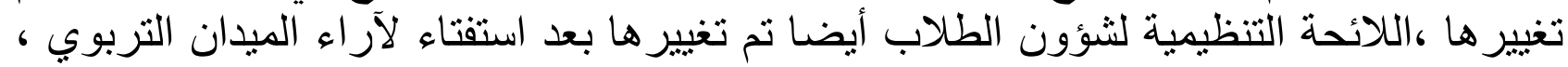

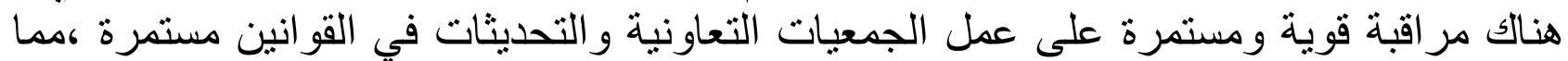
جعل المدر اء و المدير ات ينظرون بإيجابية بأن المدارس مساندة لتطبيق قانون الطفل العئ العماني.

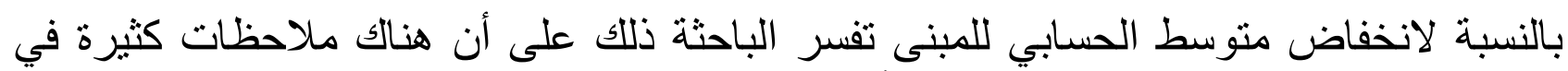

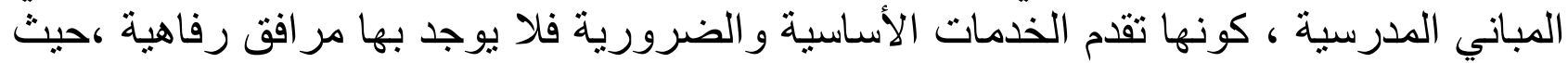

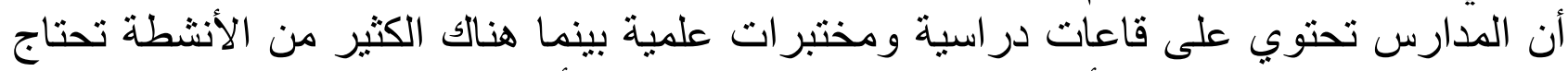

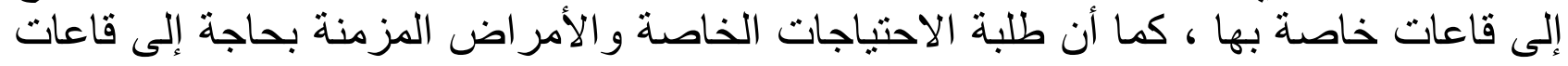

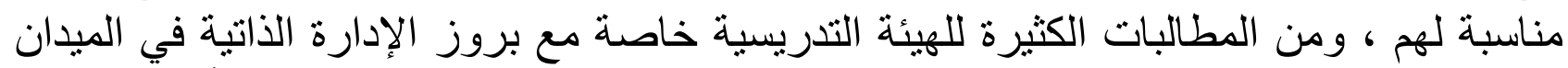

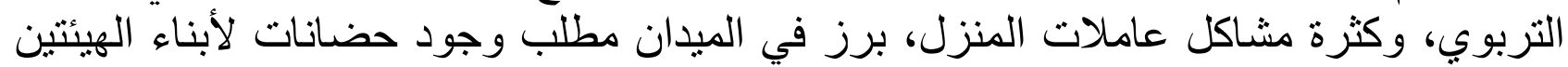

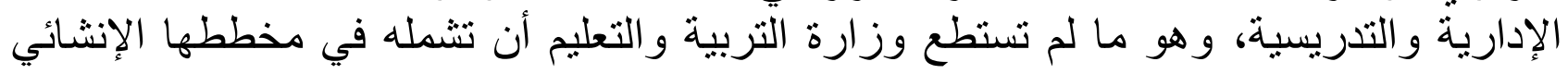
للمدارس.

نجد أن نتائج هذه الدراسة تتفق مع دراسة النبلاوي، (2012) على أن التشريعات و القوانين

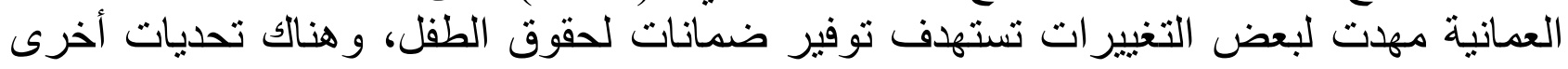

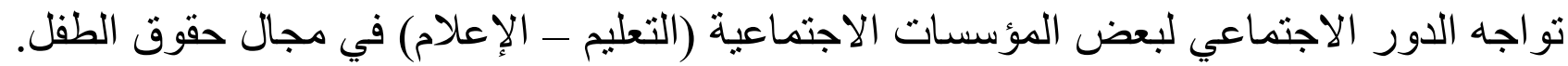

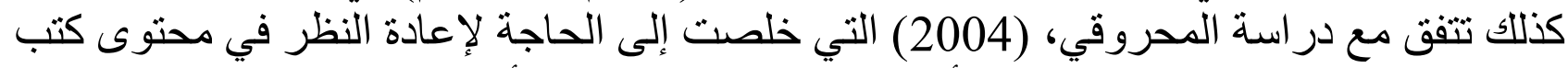

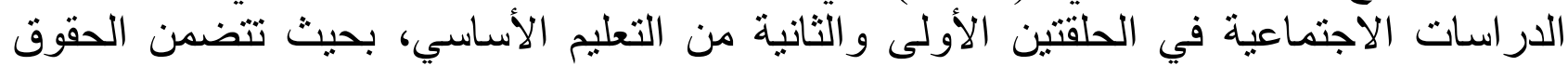

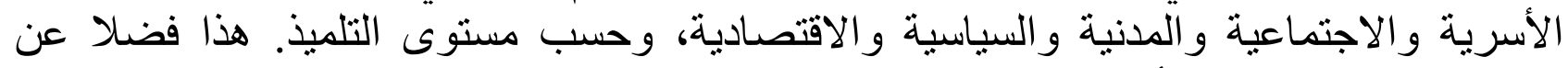

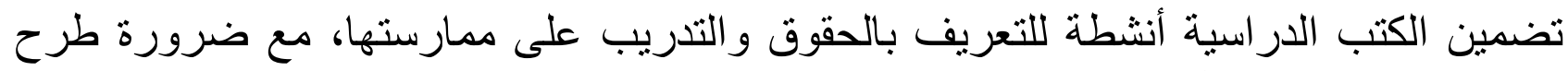

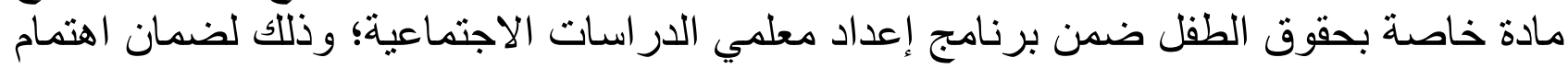

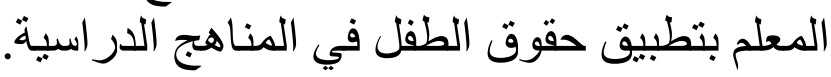

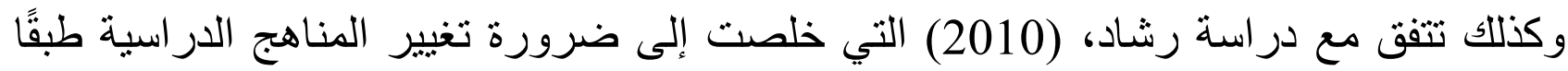

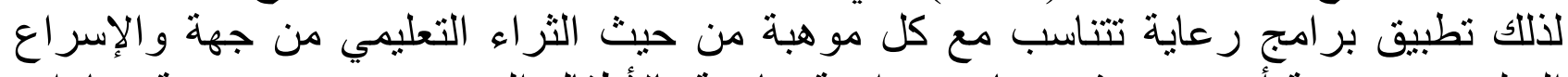

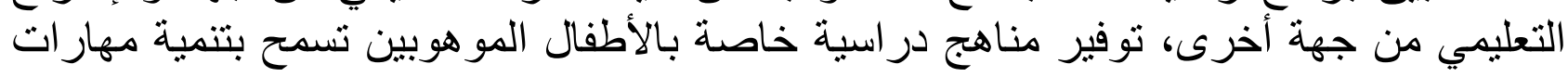

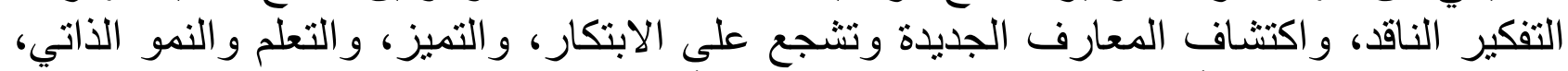

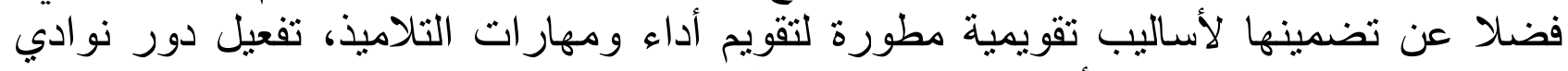

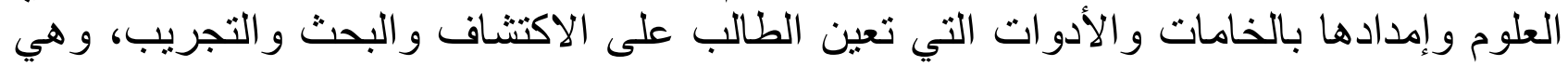
من المتطلبات الخاصة للإبداع. بالخدات

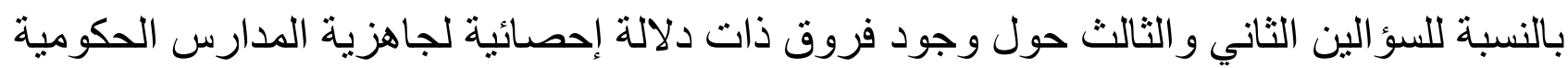

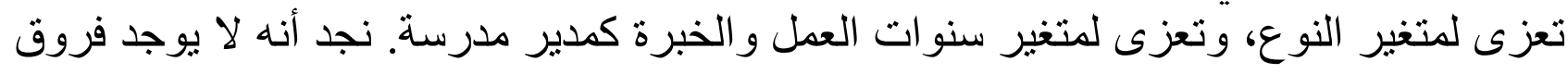


ذات دلالة إحصائية تعزى لهذين المتغيرين، وتفسر الباحثة أن هناك تقارب في آراء المدراء

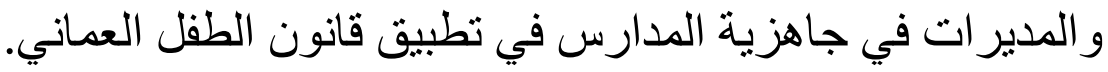

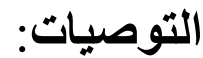

أ. إعادة تجديد المباني المدرسية بحيث نتناسب واحتياجات موظفيها، وكذلك طلبة الاحتياجات الخاصة والأمر اض المبر المزئة. ب. در اسة احتياجات الطلبة المو هوبين وتلبيتها في المدارس من ناحية المبنى. ت. تضمين المناهج الدر اسية حقوق الطفل .

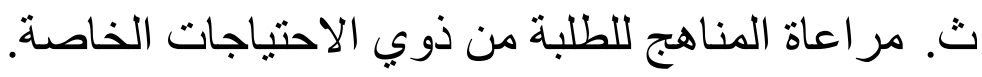
ج. مر اعاة المناهج للطلبة المو هو بين.

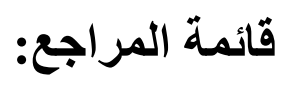

أحمد، سمير كامل. (2009). أساليب تربية الطفل. الرياض: دار الزهر اء.

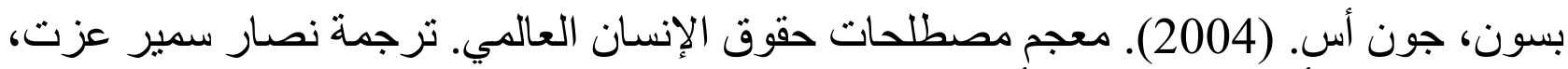
مركز الكتاب الأكاديمي، العمل الأصلي نشر في العام.

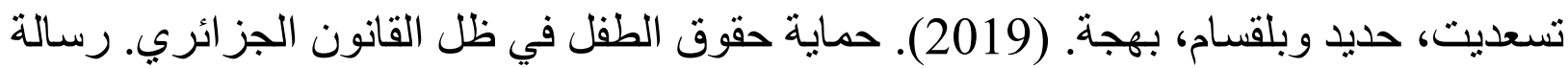

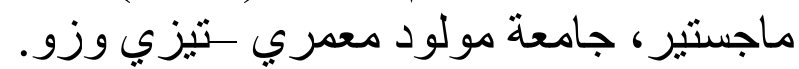
الجهورية، جميلة. (2014،ديسمبر، 31). زير التنمية الاجتماعية في حواره لـالـوالوطن) حول قانون http://epaper.alwatan.com/الطفل العماني. جريدة الوطية (31، رشاد، أنشرف حمحـ. (2010). دور التعليم في اكتشاف ور عاية الموهوبين. مجلة در اسات عربية في التربية و علم النفس ( ) (7) (20).

شني، ميلود. (2015). الحماية الدولية لحقوق الطفل .بحث مكمل لنيل شهادة الماجستير ، جامعة محمد خيضر ، الجز ائر. صديق، ناهد و عبدالو هاب محمد. (2010).حقوق الطفل في الإسلام من المنظور النفسي الاجتماعي.

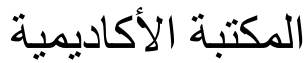
الصلح ،رياض. (2003). المنجد في اللغة والأعلام. بيروت: دار المشرق.

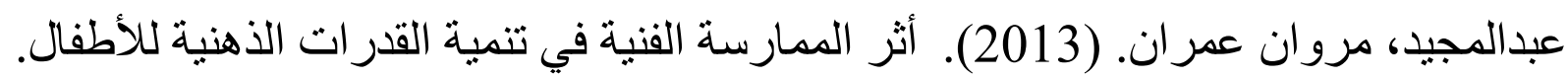

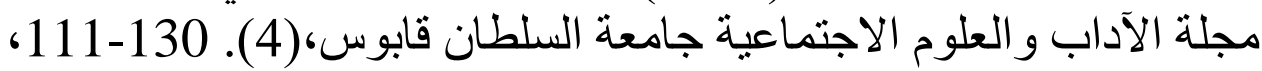

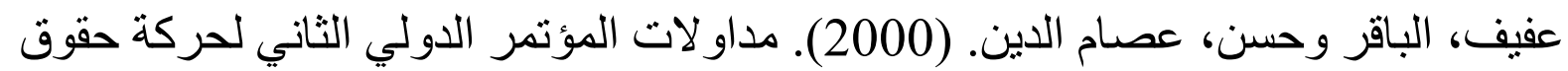

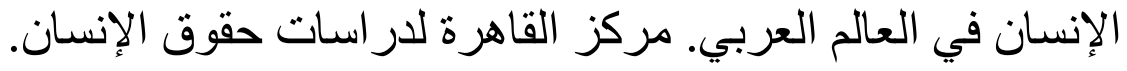

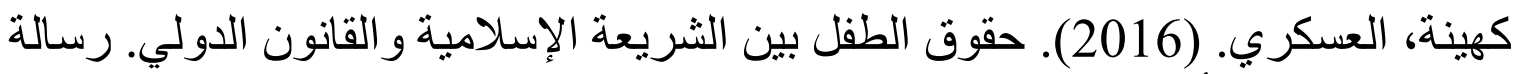
ماجستير، جامعة أحمح بوقرة مرداس (20) 
المجلس الأعلى للتخطيط (2012). تقرير التنمية البشرية: عُمان، مسقط: المجلس الأعلى للتخطيط.

$$
\text { مجمع اللغة العربية.( } 1989 \text { ).المعجم الوسيط. الإسكندرية: دار الدعوة }
$$

المحروقي، ماجد ناصر. (2004). حقوق الطفل في كتب الدر اسات الاجتماعية بمرحلة التعليم

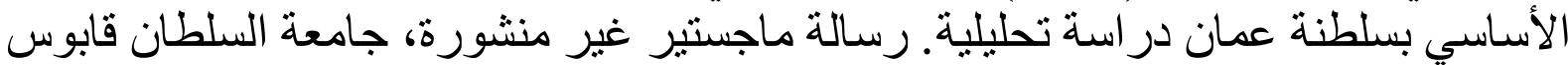

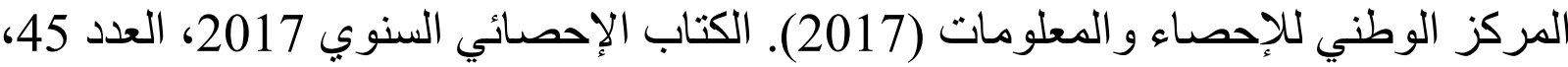

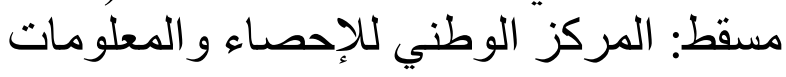

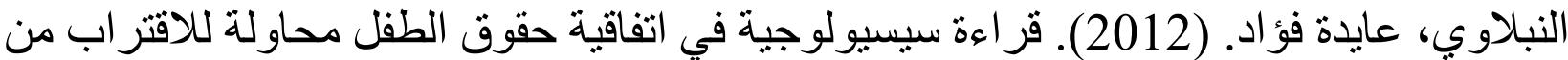

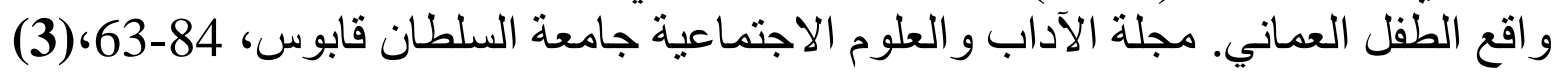

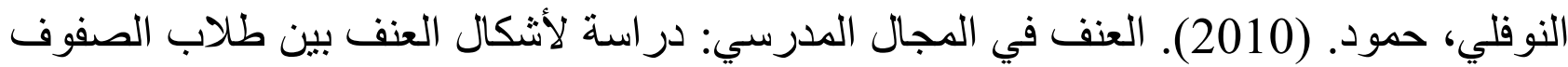

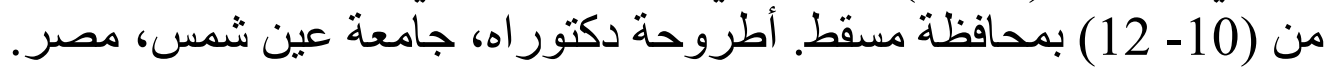

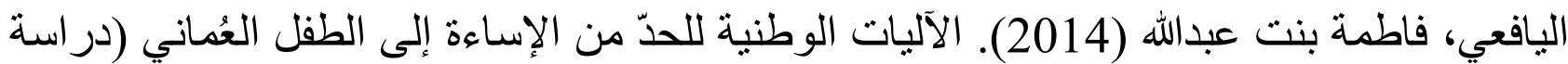

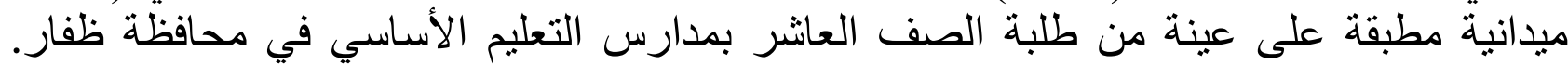
مسقط: اللجنة الوطنية لحقوق الإنسان.

\section{REFERENCES IN ROMAN ALPHABET}

'Ahmad, Samir Kaml. (2009). 'Asalib Tarbiat Altifli. Alriyad: Dar Alzhra'.

Busun, Jun 'As. (2004). Maejam Mustalahat Huquq Al'iinsan Alealami. Tarjamat Nsar Samir Eazat, Markaz Alkitab Al'akadimi, Aleamal Al'aslii Nashr fi Aleam.

Tasedit, Hadid Wabilqsam, Bahjat. (2019). Himayat Huquq Altifl fi Zili Alqanun Aljzayri. Risalat Majstir, Jamieat Mawlud Maeamari -Tayzii Wazu.

Aljuhuriat, Jamilt. (2014, Dis. 31). Zyr Altanmiat Alaijtimaeiat fi Hiwarih La(Alwtn) Hawl Qanun Altifl Aleamani. Jaridat Alwatan Http://Epaper.Alwatan.Com/

Rashad, 'Ashraf Mhmd. (2010). Dawr Altaelim fi Aiktishaf Warieayat Almawhubin. Majalat Dirasat Earabiat fi Altarbiat Waealam Alnafs 2 (7).

Shani, Maylawd. (2015). Alhimayat Alduwaliat Lihuquq Altafli. Bahath Mkml Linayl Shahadat Almajstiri, Jamieat Muhamad Khayadir, Aljazayir.

Sadiq, Nahid Waeabdaluhab Muhmid. (2010).Huquq Altifl fi Al'islam min Almanzur Alnafsii Alaijtimaei. Almaktabat Al'akadimia.

Alslh ,Rayad. (2003). Almanjad fi Allughat Wal'aelam. Biuruta: Dar Almushriq.

Eabdalmjid, Marwan Eumran. (2013). 'Athar Almumarasat Alfaniyat fi Tanmiat Alqudrat Aldhhnyt Lil'atfal. Majalat Aladab Waleulum Alaijtimaeiat Jamieat Alsultan Qabws,(4),111-130.

Eafifa, Albaqir Wahasan, Eisam Aldiyn. (2000). Mudawalat Almutamar Alduwalii Alththani Liharakat Huquq Al'iinsan fi Alealam Alearabii. Markaz Alqahrt Lidirasat Huquq Al'iinsan.

Kahinat, Aleaskri. (2016). Huquq Altifl Bayn Alshryet Al'iislamiat Walqanun Alduwli. Risalat Majstyr, Jamieatan 'Amhamad Biwaqrat Mirdas.

Almajlis Al'aelaa Liltakhtit (2012). Taqrir Altanmiat Albashariat: Euman, Msqt: Almajlis Al'aelaa Liltakhtit.

Majmae Allughat Alerabia.( 1989 ).Almaejam Alwasit. Al'iiskandariat: Dar Aldaewa

Almahruqi, Majid Nasir. (2004). Huquq Altifl fi Kutib Aldirasat Alaijtimaeiat Bimarhalat Altaelim Al'asasii Bisaltanat Eamman Dirasatan Tahlilia. Risalat Majstyr Ghyr Manshurati, Jamieat Alsultan Qabws. 
Almarkaz Alwataniu Lil'iihsa' Walmelwmat (2017). Alkitab Al'iihsayiya Alsanawia 2017, Aleadad 45, Msqt: Almarkaz Alwatanii Lil'iihsa' Walmelwmat.

Alnablawi, Eayidat Fuaad. (2012). Qara'atan Sisyulujiat fi Aitifaqiat Huquq Altifl Muhawalatan Lilaiqtirab Min Waqie Altifl Aleamani. Majalat Aladab Waleulum Alaijtimaeiat Jamieat Alsultan Qabus, (3),63-84

Alnuwafliu, Hmud. (2010). Aleunf fi Almajal Almdrsy: Dirasatan Li'ashkal Aleunf Bayn Tullab Alsufuf min (1012) Bimuhafazat Masqat. 'Atrawhat Dukturahu, Jamieat Eayan Shams, Misr.

Alyafiei, Fatimat Bnt Eibdallh (2014). Alaliat Alwataniat Llhd Min Al'iisa'at 'lilaa Altifl Aleumany (Draasat Maydaniat Mutabaqat Ealaa Eayinat min Tlbt Alsafi Aleashir Bimadaris Altaelim Al'asasii fi Muhafazat Zufar. Msqt: Allajnat Alwataniat Lihuquq Al'iinsan. 